\title{
Antitumor Effect of Hyperoside Loaded in Charge Reversed and Mitochondria-Targeted Liposomes
}

\author{
Yufei Feng' \\ Guozhao Qin' \\ Shuyuan Chang' \\ Zhongxu Jing ${ }^{2}$ \\ Yanyan Zhang (iD ${ }^{\prime}$ \\ Yanhong Wang' \\ 'Key Laboratory of Chinese Materia \\ Medica in Ministry of Education, \\ Heilongjiang University of Chinese \\ Medicine, Harbin, Heilongjiang, People's \\ Republic of China; ${ }^{2}$ Heilongjiang \\ Provincial Administration of Traditional \\ Chinese Medicine, Harbin, Heilongjiang, \\ People's Republic of China
}

Correspondence: Yanhong Wang

Tel +8645I-87266893

Email 799378826@qq.com
Introduction: Hyperoside (HYP), a flavonol glycoside compound, has been shown to significantly inhibit the proliferation of malignant tumors. Mitochondria serve as both "energy factories" and "suicide weapon stores" of cells. Targeted delivery of cytotoxic drugs to the mitochondria of tumor cells and tumor vascular cells is a promising strategy to improve the efficacy of chemotherapy.

Objective: We report a novel dual-functional liposome system possessing both extracellular charge reversal and mitochondrial targeting properties to enhance drug accumulation in mitochondria and trigger apoptosis of cancer cells.

Methods: L-lysine was used as a linker to connect 2,3-dimethylmaleic anhydride (DMA) and 1,2-distearoyl-sn-glycero-3-phosphoethanolamine (DSPE) to yield a new compound, DSPE-Lys-DMA (DLD). Then, DLD was mixed with other commercially available lipids to form charge reversed and mitochondria-targeted liposomes (DLD-Lip). The size, morphology, zeta potential, serum stability, and protein adsorption of the HYP loaded DLD-Lip (HYP/DLD-Lip) were measured. The release profile, cellular uptake, in vitro and in vivo toxicity, and anticancer activity of HYP/DLD-Lip were investigated.

Results: The results showed that the mean diameter of the liposomes was less than $200 \mathrm{~nm}$. The zeta potential of the liposomes was negative at $\mathrm{pH}$ 7.4. However, the zeta potential was positive at weak acidic $\mathrm{pH}$ values with the cleavage of the DMA amide. The charge reversion of HYP/DLD-Lip facilitated the cellular internalization and mitochondrial accumulation for enhanced antitumor effect. The strongest tumor growth inhibition (TGI 88.79\%) without systemic toxicity was observed in DLD/HYP-Lips-treated CBRH-7919 tumor xenograft $\mathrm{BALB} / \mathrm{C}$ mice.

Conclusion: The charge reversed and mitochondria-targeted liposomes represented a promising anticancer drug delivery system for enhanced anticancer therapeutic efficacy.

Keywords: mitochondria-targeted, liposome, charge reversal, antitumor, hyperoside

\section{Introduction}

Traditional Chinese medicine has a long history of tumor treatment, including paclitaxel and vincristine, which have significant antitumor effects and have been widely used clinically. ${ }^{1-3}$ In recent years, HYP, a flavonol glycoside compound extracted from Hypericum perforatum and Phyllanthus rhizoma, have been shown to significantly inhibit the proliferation of malignant tumors. ${ }^{4,5}$ The anti-tumor mechanism of HYP occurs primarily through the regulation of calcium-related mitochondrial pathways. ${ }^{6}$ Mitochondrial calcium ion overload can induce cytochrome $\mathrm{C}$ and apoptosis-inducing factors to be released from the mitochondria into the cytoplasm, eventually leading to apoptosis. ${ }^{7,8}$ However, as with most 
chemotherapy drugs, some disadvantages of HYP, such as low solubility and lack of mitochondrial targeting, limit its further application. ${ }^{9,10}$ Therefore, it is urgently important to design and prepare a safe and effective drug delivery system to improve the anti-tumor effect of HYP.

Designing a tumor microenvironment-stimulated drug delivery system based on the unique microenvironment of tumor tissue, such as stimulating responsive nanoparticles, microcapsules, polymer-drug conjugates, and prodrugs can be expected to improve the effect of anticancer drugs. ${ }^{11-13}$ Liposomes, which are often used as carriers of anti-tumor drugs, are vesicles with a cell membrane structure composed of phospholipids and cholesterol. The carrier, because of its good biocompatibility and degradability, can be enhanced by penetration and retention (EPR) in the tumor. This has been extensively studied because of the accumulation of tumor sites and the ability to load hydrophilic and hydrophobic drugs. ${ }^{14,15}$ However, with circulation in the blood stream, liposomes are easily captured and cleared by the reticuloendothelial system and the mononuclear macrophage system. Polyethylene glycol (PEG) modification can increase the circulation time of liposomes in the blood, ${ }^{16,17}$ but its existence will affect the efficiency of drug entry into the cell. Because the metabolism of tumor tissues mainly depends on anaerobic glycolysis, its metabolites produced by respiration, lactic acid and $\mathrm{CO}_{2}$, cause the acidification of the tumor microenvironment. Tumor tissue has the characteristics of low $\mathrm{pH}$, which is manifested in the lower $\mathrm{pH}$ value (6.8) of tumor cell interstitium compared with the $\mathrm{pH}$ value (7.4) of normal tissue; the $\mathrm{pH}$ value of lysosomes is $4.5{ }^{18}$ This allows for the preparation of liposomes with controllable $\mathrm{pH}$-responsive to increase the possibility of anticancer activity. Accordingly, more studies have focused on the functionalization of liposomes with a PEG deshielding mechanism with long circulation characters by a degradable $\mathrm{pH}$-sensitive bond between PEG and lipids, such as hydrazone and hydrazine bonds. ${ }^{19-25}$ In an acidic environment, the rupture of acid-sensitive chemical bonds will remove PEG on the liposome surface and enhances cellular uptake. ${ }^{26}$ Liposomes also can be decorated with carboxylic acid amide ${ }^{27}$ or maleic anhydride amide, ${ }^{28,29}$ which can be used to achieve charge reversed effect. In blood, liposomes with negative charge can avoid nonspecific protein adsorption to prolong the circulation time. However, when these liposomes exposed in the weakly acidic environment of the tumor tissue, the amide bond will be destroyed to induce positive charge on the surface of the liposomes, which significantly increases cellular internalization of liposomes. ${ }^{30}$

Based on the characteristics of the tumor tissue microenvironment and effect of HYP on mitochondria, this study constructed a new type of liposomal drug delivery system. A pH-responsive DSPE-Lys-DMA (DLD) lipid was designed. L-lysine was used as a linker to connect 2 , 3-dimethylmaleic anhydride (DMA) and 1.2-distearoyl-snglycero-3-phosphoethanolamine (DSPE) to yield a new compound, DLD. The pH-responsive DLD was mixed with other commercially available lipids to form charge reversed, mitochondria-targeted liposomes (DLD-Lip). At $\mathrm{pH} 7.4$, liposomes are negatively charged due to the carboxyl group in 2, 3-dimethylmaleic anhydride. When DLD-Lip accumulated in tumor tissues, the weak acidity in the microenvironment destroyed the dimethylmaleamide bond and the positively charged amino groups were exposed and the surface charge of DLD-Lips was reversed from a negative to positive charge, generating an electrostatic attraction with the tumor cell membrane, which increased the uptake of tumor cells. Then, the electrostatic interaction between highly positively charged liposomes and the mitochondrial membrane $(130 \sim 150 \mathrm{mV}$, internal negative charge) caused it to accumulate in the mitochondria to achieve mitochondrial targeting, and finally triggering HYP to play its therapeutic effect (Scheme 1).

\section{Materials and Methods \\ Materials}

Hyperoside reference standard (batch number: 111521-201708) was purchased from the China Institute for the Control of Pharmaceutical and Biological Products. 1.2-Distearoyl-sn-glycero-3-phosphoethanolamine-N-[methoxy-(polyethylene glycol)-2000] (DSPE$\mathrm{mPEG}_{2000}$ ) was purchased from Shanghai Fansheng Biological Technology Co., Ltd. Fetal Bovine Serum was purchased from Zhejiang Tianhang Biological Technology Co., Ltd. Rat liver cancer cell line CBRH7919 cells were purchased from Shanghai Lianmai Biological Engineering Co., Ltd. Mitochondrial stripping, Caspase 3 activity assay kit, Caspase 9 activity assay kit, and Annexin V-FITC apoptosis detection kit were purchased from Biyuntian Biotechnology Co., Ltd. Female $\mathrm{BALB} / \mathrm{c}$ nude mice were purchased from the Beijing Weitong Lihua Experimental Animal Technology Co., Ltd. (Beijing, China, license number: SCXK (Beijing) 2016-0006, initial weight 18-22 g), and placed in the 


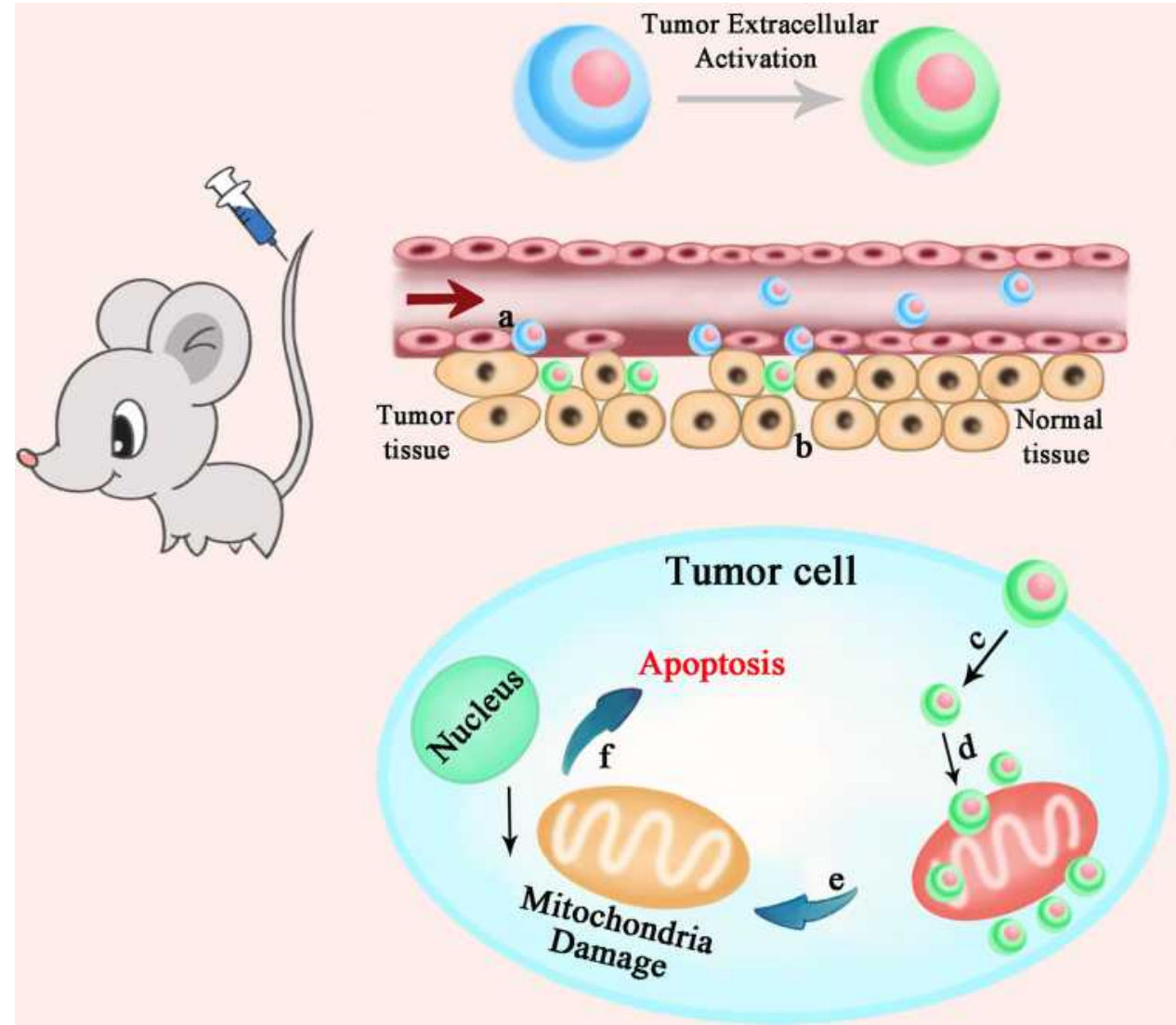

Scheme I Illustration of dual-functional liposome (DLD-Lip) with $\mathrm{pH}$ response to the tumor microenvironment and mitochondrial-targeting anticancer drug delivery. a) $\mathrm{pH}$-response of DLD in mildly acidic tumor microenvironment for surface charge conversion. b) Positive charge of liposome improved cellular uptake. c) Internalization of liposomes into tumor cells. d) Binding to mitochondria. e) HYP play its therapeutic effect in mitochondria. f) Mitochondria apoptosis.

animal experiment center. The relevant operations of all experimental animals were approved and carried out in accordance with the relevant requirements of the Animal Experimental Management Committee of Heilongjiang University of Traditional Chinese Medicine.

\section{Synthesis of DSPE-Lys-DMA (DLD) Synthesis of DSPE-Lys}

DSPE (1.50 g, $2.00 \mathrm{mmol})$ was dissolved in anhydrous trichloromethane $(30 \mathrm{~mL})$ under nitrogen atmosphere. DIPEA (2.00 $\mathrm{mL}, 12.00 \mathrm{mmol}$ ) was added to the solution under stirring at $0^{\circ} \mathrm{C}$. Boc-L-Lys(Boc)-OH $(0.83 \mathrm{~g}, 2.40 \mathrm{mmol})$, HOBT $(0.32$ $\mathrm{g}, 2.40 \mathrm{mmol})$, and HBTU $(0.91 \mathrm{~g}, 2.40 \mathrm{mmol})$ dissolved in anhydrous DMF (5 mL) was added to the reaction flask containing DSPE. The solution was stirred under nitrogen in an ice bath for $30 \mathrm{~min}$ and at room temperature for another $24 \mathrm{~h}$. The solvents were removed using rotary evaporation and the mixture was purified via column chromatography (silica, $\mathrm{CH}_{2} \mathrm{Cl}_{2}$ : $\mathrm{MeOH}=10: 1)$. The product DSPE-(Boc)-L-Lys-Boc was dried in a vacuum.
The received DSPE-(Boc)-L-Lys-Boc was dissolved in anhydrous dichloromethane (DCM)/TFA (1:1, $10 \mathrm{~mL})$. The solution was stirred under nitrogen for $4 \mathrm{~h}$. The solvents were removed via rotary evaporation, and the sample was then dried in vacuum for $1 \mathrm{~h}$. The product was precipitated in anhydrous diethyl ether. The white precipitate was three times washed with anhydrous diethyl ether and collected using centrifugation. DSPE-Lys, with a yield of $80.23 \%$, was obtained after vacuum drying. The ${ }^{1} \mathrm{H}$ NMR spectrum of DSPE Lys was shown in Supporting Information.

\section{Synthesis of DSPE-Lys-DMA}

Under the protection of nitrogen, DSPE-Lys (1.00 g, 1.14 $\mathrm{mmol}$ ) was dissolved in $20 \mathrm{~mL}$ of anhydrous dichloromethane. In an ice bath, Triethanolamine (TEA, $0.58 \mathrm{~g}$, $5.71 \mathrm{mmol})$ and DMA (0.57 g, $4.56 \mathrm{mmol})$ dissolved in dichloromethane were injected into the reaction system, and the reaction system was stirred at room temperature for 24 hours. After the reaction, the organic solvent was removed and the crude product was recrystallized in 
acetone solution at $4^{\circ} \mathrm{C}$. Finally, the obtained precipitate DSPE-Lys-DMA was washed three times with ether and then dried in a vacuum. The yield was $30 \%$. H-Nuclear Magnetic Resonance ( $\left.{ }^{1} \mathrm{H}-\mathrm{NMR}\right)$ and Electrospray Ionization-Mass Spectrometry (ESI-MS) were used to confirm the structure of DSPE-Lys. The ${ }^{1} \mathrm{H}$ NMR spectrum of DSPE-Lys-DMA was shown in Supporting Information.

\section{Preparation and Characterization of Liposomes}

HYP-loaded liposomes were prepared using the thin-film hydration method. Soy lecithin (SPC), cholesterol, DLD, DSPE- $\mathrm{mPEG}_{2000}$ and HYP (mass ratio, 8:2:2.5:1.5:1) were dissolved in a round bottom flask using chloroform/ methanol as a mixed solvent $(2: 1, \mathrm{v} / \mathrm{v})$. The organic solvent was removed using a rotary evaporator to form a homogeneous film on the bottom of the bottle and it was dried under vacuum overnight. The overnight-dried film was hydrated in phosphate buffered saline (PBS, $\mathrm{pH}$ 7.4) or ultrapure water to a phospholipid concentration of $1.6 \mathrm{mg} / \mathrm{mL}$. The liposomes were sonicated in a water bath at $37^{\circ} \mathrm{C}$ for 10 minutes, then further probed at $40 \mathrm{~W}$ for $100 \mathrm{~s}$ to prepare DLD/HYP-Lip. DLD/HYP-Lip $(0.5 \mathrm{~mL})$ was added to $2.0 \mathrm{~mL}$ of ultrapure water, placed in an ultrafiltration centrifuge tube, and centrifuged at $4000 \mathrm{rpm}$ for $20 \mathrm{~min}$. Then, the lower layer of the solution was removed and the concentration of HYP was determined by high-performance liquid chromatography (HPLC). The encapsulation efficiency and drug loading were calculated according to the following formulas:

$$
\begin{gathered}
E E \%=W / W_{0} \times 100 \% \\
D L \%=W_{\text {drug }} / W_{\text {total }} \times 100 \%
\end{gathered}
$$

W: content of HYP in the liposome after centrifugation

$\mathrm{W}_{0}$ : content of HYP in the liposome

$W_{\text {drug }}$ : the weight of HYP

W total: the weight of HYP, cholesterol, and phospholipids

The average particle size of the liposomes was measured using a Dynamic Light Scattering (DLS) Analyzer. For the sample, $100 \mu \mathrm{L}$ liposomes (phospholipid concentration $5 \mathrm{mg} / \mathrm{mL}$ ) were diluted in $1 \mathrm{~mL}$ buffer solution.

DLD/HYP-Lip $(200 \mu \mathrm{L})$ was diluted to a certain multiple, added to a special copper mesh, and stained with phosphotungstic acid. The sample was then air dried, followed by observation of the shape of the particles under a transmission electron microscope.

\section{The $\mathrm{pH}$-Induced Potential Changes}

To investigate the potential change of DLD/-Lip in different $\mathrm{pH}$ buffer solutions, $1 \mathrm{~mL}$ of SPC-Lip and DLD/-Lip were added to $15 \mathrm{~mL}$ of PBS solution ( $\mathrm{pH} \mathrm{7.4,} \mathrm{pH} 6.8$ ) and acetic acid buffer solution (incubate at $\mathrm{pH} 5.5$ and $\mathrm{pH} 4.5$ ) at $37^{\circ} \mathrm{C}$, at $0,2,4,6,8$, and $12 \mathrm{~h}$. A $1.5 \mathrm{~mL}$ sample was taken for potential measurement.

\section{Differential Scanning Calorimetry Analysis}

To study the interaction between drugs and other excipients in the preparation of liposomes, the crystal characteristics of HYP and other excipients were analyzed by differential scanning calorimetry (DSC). An appropriate amount of the sample was weighed and placed in an aluminum crucible, and the crucible cap was sealed. A blank crucible was used as a reference. The temperature ranged from $40^{\circ} \mathrm{C}$ to $300^{\circ} \mathrm{C}$, the heating rate was $20^{\circ} \mathrm{C} /$ min, and the shielding gas (high purity nitrogen) flow rate was $60 \mathrm{~mL} / \mathrm{min}$. SPC, cholesterol, DSPE-PEG, DLD, HYP, DLD/HYP-Lip, and DLD/HYP-Lip physical mixed samples were analyzed, and the differential scanning calorimeter characteristic curves of each sample were recorded.

\section{Serum Stability Study}

The stability of the liposomes in serum was assessed by measuring the change in particle size of SPC-Lip and DLD-Lip in fetal bovine serum. Liposomes with a phospholipid concentration of $5 \mathrm{mg} / \mathrm{mL}$ were mixed with an equal volume of fetal bovine serum and incubated at $37^{\circ} \mathrm{C}$. At $1,4,8$, and $24 \mathrm{~h}, 100 \mu \mathrm{L}$ of the sample was taken for particle size determination. The liposome particle size at $0 \mathrm{~h}$ is the particle size measured in a PBS solution at $\mathrm{pH} 7.4$.

\section{Liposome Adsorption Test}

Bovine serum albumin (BSA) was used as a model protein to detect the protein adsorption capacity of liposomes. The liposomes were placed in a $\mathrm{pH} 7.4$ or 6.8 phosphate buffer solution (phospholipid concentration of $0.15 \mathrm{mg} / \mathrm{mL}$, protein concentration of $0.25 \mathrm{mg} / \mathrm{mL}$ ) containing BSA and incubated at $3^{\circ} \mathrm{C}$ for $2 \mathrm{~h}$ or $4 \mathrm{~h}$, respectively. Three hundred microliters of the solution was centrifuged at 13,000 $\times \mathrm{g}$ for $15 \mathrm{~min}$. The aggregates of adsorbed protein settled at the bottom, and the supernatant contains unadsorbed protein. BSA was used as the standard solution and the 
protein content in the supernatant was determined using the bicinchoninic acid (BCA) protein kit. Then, $25 \mu \mathrm{L}$ of the sample was added to a 96-well plate and $200 \mu \mathrm{L}$ of the $\mathrm{BCA}$ reaction solution was added. The microplate reader measures the absorbance at $570 \mathrm{~nm}$.

\section{Determination of in vitro Release Rate}

The in vitro release of DLD/HYP-Lip in the release medium was determined by dialysis. Specifically, $0.1 \mathrm{~mL}$ DLD/HYP-Lip and free HYP solution (HYP content $0.5 \mathrm{mg} / \mathrm{mL}$ ) was added to a pre-treated dialysis bag (molecular weight cut off $6000-8000 \mathrm{Da}$ ) and placed in $50 \mathrm{~mL}$ of release medium. The sample was then centrifuged at $50 \mathrm{rpm}$ at $37^{\circ} \mathrm{C}$. The release medium was $0.1 \%$ Tween 80 in PBS solution ( $\mathrm{pH} 7.4,6.8)$ and $0.1 \%$ Tween 80 acetate buffer solution ( $\mathrm{pH} 5.5,4.5$ ). At $0.5,1,2,4,8,12$, and 24 $\mathrm{h}, 0.5 \mathrm{~mL}$ of the release medium was collected and equal volumes of fresh release medium were added to the drug release medium. The content of HYP in the sample was measured, and the cumulative release at each time point was calculated according to the following formula. Then a release curve was drawn.

$$
E_{r}=\frac{V_{e} \sum_{i-1}^{n-1} C_{i}+\mathrm{V}_{0} C_{n}}{M_{\mathrm{drug}}} \times 100 \%
$$

Where $E_{r}$ represents the cumulative release of HYP, $V_{e}$ represents the displacement volume of the release medium, $\mathrm{C}_{\mathrm{i}}$ represents the concentration of the drug released during the $\mathrm{i}$-th replacement sampling, $\mathrm{V}_{0}$ represents the volume of the release medium, and $\mathrm{Cn}$ represents the release medium in the nth sampling. The drug concentration, $M_{\text {drug }}$, represents the HYP content in the liposome.

\section{Cell Lines and Cell Culture}

CBRH-7919 cells were derived from rat hepatoma cells and are passaged compared to primary liver cancer cells, making them easier to culture in vitro. CBRH-7919 cells were cultured in 1640 medium containing $10 \%$ fetal bovine serum and $1 \%$ double antibody.

\section{Cellular in vitro Uptake Efficiency}

To observe the in vitro uptake of DLD/HYP-Lip by CBRH-7919 cells, cell uptake of DLD/HYP-Lip was examined by flow cytometry. CBRH-7919 cells were seeded in parallel in a 6 -well plate at $1 \times 10^{5}$ per well. The plate was incubated in a $37^{\circ} \mathrm{C}, 5 \% \mathrm{CO}_{2}$ cell incubator for $24 \mathrm{~h}$. After cells were attached, the original culture solution was aspirated and washed twice with
PBS. After washing the PBS was discarded and DLD/ HYP-Lip solution ( $\mathrm{pH} 7.4$ and $\mathrm{pH}$ 6.8) at a concentration of $0.5 \mu \mathrm{g} / \mathrm{mL}$ was added. Fresh medium without any added drug was used as the control group. Samples were incubated for $4 \mathrm{~h}$. After incubation, the original culture solution was aspirated, washed with cold $4^{\circ} \mathrm{C}$ PBS three times, $500 \mu \mathrm{L}$ trypsin digest was added, and then $2 \mathrm{~mL}$ complete medium was added to terminate the digestion. The adherent cells were all suspended in complete medium and centrifuged (1000 rpm, $5 \mathrm{~min}$ ). The supernatant was discarded, followed by resuspending the cells in $1 \mathrm{~mL}$ of $4^{\circ} \mathrm{C}$ PBS. The sample was then centrifuged (1000 rpm, $5 \mathrm{~min}$ ) twice, and finally the cells were dispersed in $300 \mu \mathrm{L}$ of $4^{\circ} \mathrm{C}$ PBS. These cells were then used for flow cytometry to analyze the fluorescence intensity.

\section{In vitro Cytotoxicity Study}

The in vitro cytotoxicities of free HYP, SPC/HYP-Lip, pH-sensitive DLD/HYP-Lip, and the blank DLD-Lip against CBRH-7919 cells at $\mathrm{pH} 7.4$ and $\mathrm{pH} 6.8$ were evaluated using 3-(4,5-dimethyl-thiazol-2-yl)-2,5-diphenyl-tetrazolium bromide (MTT assay). CBRH-7919 cells were inoculated in parallel with $5 \times 10^{4}$ cells per well in a 96-well plate. After incubation for $24 \mathrm{~h}$, the cells were exposed to fresh medium with a $\mathrm{pH}$ adjusted to either 7.4 or 6.8 containing blank or HYP-loaded liposomes. After 48 hours of incubation, $20 \mu \mathrm{L}$ of MTT solution $(5 \mathrm{mg} / \mathrm{mL})$ was added to each well and the sample was incubated for an additional 4 hours. The absorbance $\left(\mathrm{OD}_{490}\right)$ was measured at the wavelength of the microplate reader at $490 \mathrm{~nm}$.

\section{Co-Localization into the Mitochondria}

Mitochondria localization of SPC/HYP-Lips and DLD/ HYP-Lips in CBRH-7919 cells were observed under a laser confocal scanning microscope. CBRH-7919 cells were seeded $\left(1 \times 10^{4}\right.$ cells in each glass-bottomed dish) and cultured for $24 \mathrm{~h}$ under $5 \% \mathrm{CO}_{2}$ at $37^{\circ} \mathrm{C}$. After 24 $\mathrm{h}$ incubation, cells were treated with SPC/HYP-Lips or DLD/HYP-Lips, and cultured for another $12 \mathrm{~h}$ under the same conditions (final HYP concentration: $0.5 \mu \mathrm{g} / \mathrm{mL}$ ). After incubation, the medium was removed and the cells were washed with cold PBS three times, and then cells were stained with Mitotracker Green FM (75 nM) for 30 min under $5 \% \mathrm{CO}_{2}$ at $37^{\circ} \mathrm{C}$. Stained cells were washed with PBS three times to remove free dye and observed by CLSM. 


\section{Determination of HYP Content in} Mitochondria

CBRH-7919 cells were seeded in parallel in a six-well plate at $1 \times 10^{5}$ cells per well. The plates were incubated in a $37^{\circ} \mathrm{C}, 5 \% \mathrm{CO}_{2}$ cell incubator for $24 \mathrm{~h}$. After the cells were attached, the original culture solution was aspirated, $2 \mathrm{~mL}$ was added, and the sample was washed twice with PBS. Then, SPC/HYP-Lip, DLD/HYP-Lip solution at a concentration of $0.5 \mu \mathrm{g} / \mathrm{mL}$ was added; fresh medium without any additive was used as the control group. Samples were incubated in a cell culture incubator at $24 \mathrm{~h}$. After incubation, the original culture solution was aspirated, washed twice with cold $4^{\circ} \mathrm{C}$ PBS, and then the mitochondria were extracted using a mitochondrial stripping kit. The cells were redispersed in the mitochondrial stripping buffer solution, homogenized in a homogenizer fifteen times, the obtained suspension solution was centrifuged (13,000 rpm, $10 \mathrm{~min})$, and the supernatant was collected and centrifuged again (11,000 rpm, $10 \mathrm{~min})$. For mitochondrial separation, the desired precipitate is mitochondria, and the mitochondria were redispersed in $300 \mu \mathrm{L}$ of PBS after the supernatant was aspirated. The HYP content in the mitochondria was measured using a flow cytometer.

\section{Mitochondria-Mediated Cell Apoptosis}

\section{Pathway}

Activity Determination of Caspase 3 and Caspase 9

CBRH-7919 cells were seeded in parallel in a 6-well plate at $1 \times 10^{5}$ per well. The plate was incubated in a $37^{\circ} \mathrm{C}, 5 \%$ $\mathrm{CO}_{2}$ cell incubator for $24 \mathrm{~h}$. After the cells were attached, the original culture solution was aspirated and added. Cells were then washed twice with $2 \mathrm{~mL}$ PBS, SPC/HYP-Lip, DLD/HYP-Lip, and HYP solutions at a concentration of $20 \mu \mathrm{g} / \mathrm{mL}$ were added. Fresh medium without any added drug was the control group. Cells were then incubated for 12 h. Following the methods in the Caspase 3 and Caspase 9 activity detection kits, the cell culture solution was aspirated and used. The adherent cells were digested with $500 \mu \mathrm{L}$ of trypsin and collected into spare cell culture medium. Cells were then centrifuged (1000 rpm, $5 \mathrm{~min}$ ), the supernatant was discarded, and $2 \mathrm{~mL}$ of PBS was added to wash the cells. Then, the cells were centrifuged (1000 rpm, $5 \mathrm{~min}$ ), the supernatant was discarded, $100 \mu \mathrm{L}$ of the lysate was added, and samples were transferred into a $600 \mu \mathrm{L}$ centrifuge tube. In an ice bath, the sample was lysed for $15 \mathrm{~min}$, and centrifuged at $4^{\circ} \mathrm{C}(16,000 \mathrm{rpm}, 15$ min). The supernatant was transferred to a pre-cooled centrifuge tube in an ice bath. Then, $5 \mu \mathrm{L}$ sample was taken for determination of protein concentration following the Bradford method. Appropriate samples were added to Caspase 3 and Caspase 9 substrates, and incubated overnight at $37^{\circ} \mathrm{C}$ in the dark. The activity of Caspase 3 and Caspase 9 was calculated by ELISA at $405 \mathrm{~nm}$.

\section{Apoptosis Test}

Apoptosis of CBRH-7919 cells was measured using an Annexin V-FITC apoptosis detection kit and analyzed by flow cytometry. Cells were seeded in parallel in a 6-well plate at $1 \times 10^{5}$ per well and incubated for $24 \mathrm{~h}$. HYP, SPC/ HYP-Lip, and DLD/HYP-Lip were added to each well with $20 \mu \mathrm{g} / \mathrm{mL}$ HYP and incubated for $12 \mathrm{~h}$. After incubation, the culture solution was aspirated, washed three times with $4{ }^{\circ} \mathrm{C}$ PBS; then, $500 \mu \mathrm{L}$ trypsin digest was added, $2 \mathrm{~mL}$ complete medium was added, the digestion was terminated and centrifuged (1000 rpm, $5 \mathrm{~min}$ ). The supernatant was discarded, the cells were resuspended in PBS and centrifuged (1000 rpm, 5 min). According to the Annexin V-FITC apoptosis detection kit, the cells were resuspended in $195 \mu \mathrm{L}$ Annexin V-FITC binding solution, $5 \mu \mathrm{L}$ of Annexin V-FITC, and $10 \mu \mathrm{L}$ PI staining solution. The samples were incubated at room temperature in the dark. After $20 \mathrm{~min}$, the assay was quantified by flow cytometry.

\section{Animal Tumor Xenograft Models}

Animal experiments were performed in accordance with the Experimental Animal Administrative Committee of Heilongjiang University of Chinese Medicine (Ref. No: 2017042501). Approximately $5 \times 10^{6}$ CBRH-7919 cells suspended in PBS $(50 \mathrm{~mL})$ were subcutaneously injected into the left backs of BALB/c nude mice under anesthesia. Tumor volume (V) was calculated by measuring the length (L) and width (W), and calculated as $\mathrm{V}=\mathrm{L} \times \mathrm{W}^{2} / 2 \mathrm{~s}$. The drug was administered when the tumor was $50-100 \mathrm{~mm}^{3}$.

\section{In vivo Antitumor Efficacy}

Mice were randomly assigned into four groups $(n=5)$. Saline, HYP $(6.0 \mathrm{mg} / \mathrm{kg})$, SPC/HYP-Lip $(6.0 \mathrm{mg} / \mathrm{kg}$, calculated by HYP content), or DLD/HYP-Lip $(6.0 \mathrm{mg} / \mathrm{kg}$, calculated by HYP content) was administrated via tail vein injection. ${ }^{31}$ Different formulations were injected at 12, 14, 16, 18, and 20 days after CBRH-7919 cell injection. Mice were weighed and tumors were measured every 2 days. Mice were sacrificed on day 25 after tumor inoculation and tumors were removed and then embedded in paraffin 
and cut with a microtome (5-mm thick) before staining with hematoxylin and eosin (HE). For quantification of proliferative cells, Ki67 was assessed with Anti-Ki67 [SP6] antibody (Abcam, England). The Ki67 index was calculated as the ratio of proliferative cells to total cells in each field, using five random fields. For quantification of apoptotic cells, tdt-mediated dutp nick-end labeling (TUNEL) assays were used with the in situ cell death detection kit-POD (Roche Group, Switzerland). The apoptotic index was calculated as the ratio of apoptotic cells to total cells in each field, using five random fields.

\section{In vivo Toxicity}

Healthy male BALB/c were randomly assigned into four groups $(\mathrm{n}=5)$, and saline, HYP $(6.0 \mathrm{mg} / \mathrm{kg}), \mathrm{SPC} / \mathrm{HYP}-$ Lip $(6.0 \mathrm{mg} / \mathrm{kg}$, calculated by HYP content), or DLD/ HYP-Lip $(6.0 \mathrm{mg} / \mathrm{kg}$, calculated by HYP content) was administrated via tail vein injection. Different formulations were injected and mice were weighed every 2 days. Then, animal behaviors were assessed.

After 7 days post-dosing, mice were allowed to recover and were weighed every day. After sacrifice, the liver, heart, spleen, lungs, and kidneys were removed and washed with PBS, fixed in 4\% formaldehyde, embedded in paraffin, and cut with a microtome (5-mm thick) for HE staining.

\section{HYP Quantification Using HPLC}

HYP was measured via HPLC using a Shimadzu HPLC system consisting of a LC-20AT-pump and a SPD-20A Diode array detector (Shimadzu Technologies). A Diamonsil C-18 column $(250 \mathrm{~mm} \times 4.6 \mathrm{~mm}, 5 \mu \mathrm{m}$; DIKMA Technologies) and a detector wavelength of 360 $\mathrm{nm}$ were used. A solvent mixture of acetonitrile - $0.1 \%$ phosphoric acid solution $(22: 78, \mathrm{v} / \mathrm{v})$ was used as an eluent, and the flow rate was $1.0 \mathrm{~mL} / \mathrm{min}$.

\section{Statistical Analysis}

All data are presented as means $\pm \mathrm{SD}$. A Student's $t$-test or One-way analysis of variance (ANOVA) was used to determine statistical significance. Statistical significance was set at $* p<0.05$, and $* * p<0.01$ indicates highly significant differences.

\section{Results and Discussion Synthesis of DSPE-Lys-DMA (DLD)}

The synthetic route of DSPE-Lys-DMA was shown in Scheme S1 of Supporting Information. The carboxylic group of Boc-L-Lys(Boc)-OH was conjugated to the primary amine group of DSPE and deprotected using trifluoroacetic acid. DMA was connected to the amino groups of the DSPE-Lys using an amidation reaction. The DSPE-Lys -DMA was characterized using matrix assisted laser desorption ionization time-of-flight mass spectroscopy (MALDI-TOF MS) and ${ }^{1} \mathrm{H}$ NMR in Supporting Information.

\section{Characterization of Liposomes}

The size, polymer dispersity index (PDI), encapsulation efficiency, and drug loading of blank and HYP-loaded liposomes (SPC-Lip, DLD-Lip, SPC/HYP-Lip, and DLD/ HYP-Lip) are shown in Table S1 of Supporting Information. The average diameter of the two blank liposomes was similar, approximately $110 \mathrm{~nm}$, while the average diameter of the two HYP drug-loaded liposomes was about $130 \mathrm{~nm}$. Because the drug is encapsulated in the lipid bilayer of liposomes, the particle size of HYP liposomes was larger than that of blank liposomes. ${ }^{24,32}$ The DLD-Lips meter showed higher encapsulation efficiency and drug loading. The encapsulation efficiency of liposomes obtained by reconstitution of long-circulating and $\mathrm{pH}$-sensitive hyperoside liposomes was $(94.36 \pm 1.52) \%$, which was greater than $90 \%$, indicating the optimal formulation of liposomes and a strong encapsulation ability for HYP. ${ }^{33}$ The drug loading of the liposomes obtained after reconstitution was $8.5 \%$, indicating that the liposome prepared by the optimal formulation has a strong drugloading ability for HYP. ${ }^{34,35}$ PDI is $(0.164 \pm 0.062)$, indicating that the particle size of liposomes is very uniform. Transmission Electron Microscope (TEM) was used to perform a morphological analysis of DLD-Lips loaded with DLD/HYP-Lips, the liposome was rounded and spherical, as shown in Figure 1A.

\section{Serum Stability Study}

The stability of SPC-Lip and DLD-Lip in serum was examined using an environmental mimic physiological condition containing $50 \%$ fetal bovine serum. The results are shown in Figure 1B. In $\mathrm{pH} 7.4$ serum, the average particle size and distribution of DLD-Lips hardly changed after 24 hours (PDI $=0.19 \pm 0.03$ ). These results suggest that DLD-Lips do not aggregate in the serum solution, there are no significant change in the average particle size and distribution of sulfate. ${ }^{33}$ 
A
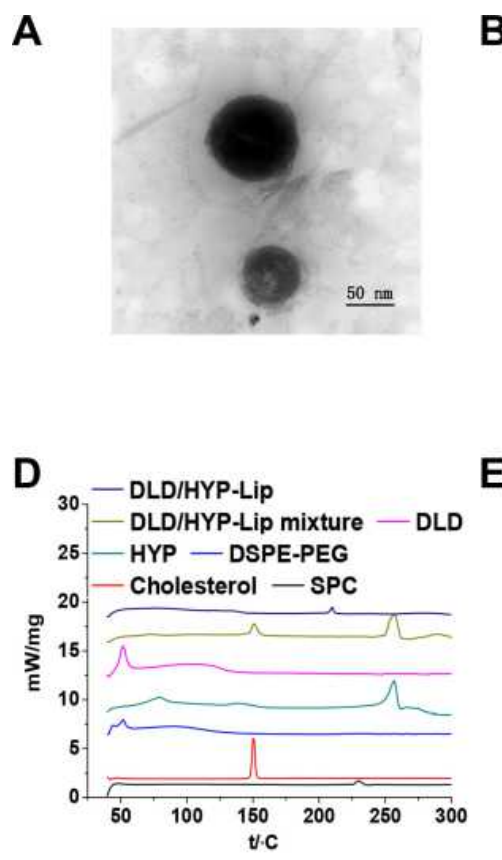

B

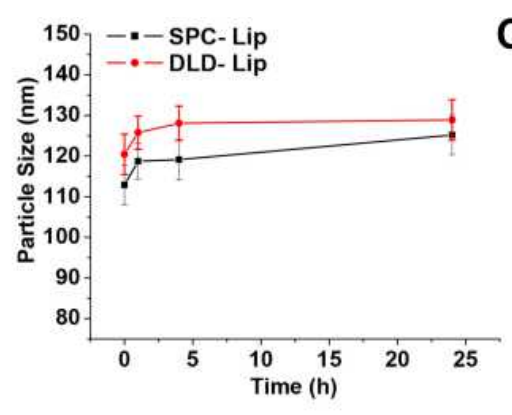

E

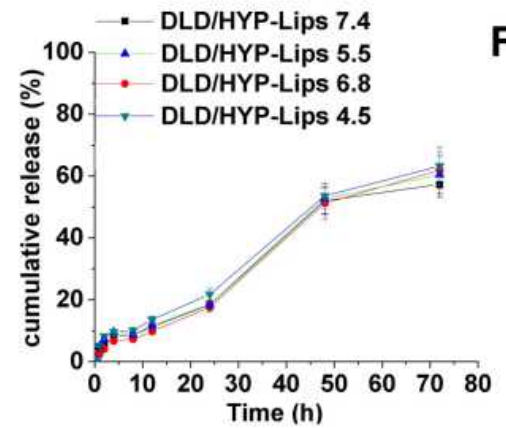

C

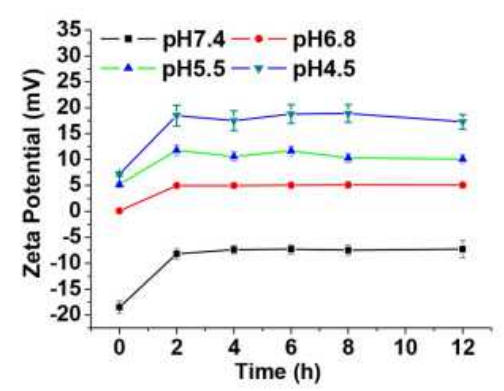

$\mathbf{F}$

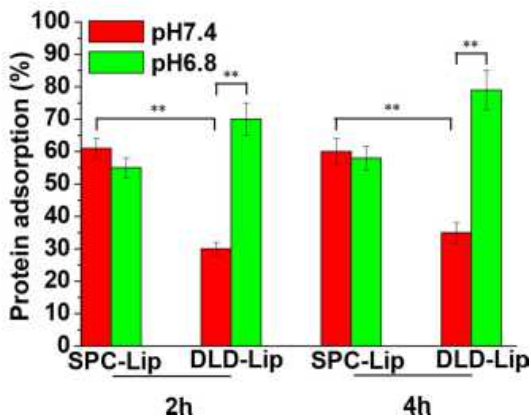

Figure I Physicochemical properties of liposomal formulations. TEM image of DLD/HYP-Lips (scale bar = 200 nm) (A). Changes in particle size of SPC-Lip and DLD-Lip in fetal bovine serum (means \pm SD, $n=3$ ) (B). Zeta potential variation of DLD/HYP-Lips at different pH values (C). DSC Curve of DLD/HYP-Lip, DLD, HYP, Cholesterol, SPC, DSPE-PEG, and physical mixed sample composed of DLD/HYP-Lip (D). Cumulative release of DLD/HYP-Lip in the release medium (means \pm SD, $n=3)$ (E). Bovine serum albumin (BSA) adsorption on liposomes after 2 and $4 \mathrm{~h}$ incubation at $37^{\circ} \mathrm{C}, \mathrm{pH} 7.4$ or 6.8 (means $\pm \mathrm{SD}, \mathrm{n}=3$ ) $(\mathbf{F})$. ** $\mathrm{p}<0.01$.

\section{The $\mathrm{pH}$ Sensitivity of DLD-Lips}

To demonstrate that DLD-Lips changed surface properties in response to tumor extracellular and intracellular environments, zeta potentials of DLD-Lips were tested when they were dispersed in buffer solutions of different $\mathrm{pH}(\mathrm{pH}$ $7.4,6.8,5.5$, and 4.5$)$. These $\mathrm{pH}$ values simulated physiological $\mathrm{pH}(\mathrm{pH} 7.4)$, the tumor micro-environment $(\mathrm{pH}$ 6.8), endosomes and lysosomes $(\mathrm{pH} 5.5)$, and latelysosomes $(\mathrm{pH} 4.5)$. As shown in Figure 1C, when the $\mathrm{pH}$ value was 7.4, the zeta potential of DLD-Lips was negative, when $\mathrm{pH}$ decreased to 6.8, DLD-Lips surface charges immediately increased to neutral, and plateaued to $5 \mathrm{mV}$ within $1 \mathrm{~h}$, and when the $\mathrm{pH}$ values were 5.5 and 4.5, DLD-Lips maintained positively charged surfaces with zeta potentials of $\sim 10 \mathrm{mV}$ and $20 \mathrm{mV}$, respectively. In contrast, traditional liposomes (SPC-Lips) did not undergo charge conversion. This indicated that DLD-Lip was negatively charged in the circulation $(\mathrm{pH} \mathrm{7.4)}$ and did not interact as much with negatively charged plasma proteins, leading to high resistance to non-specific protein absorption and enhanced the stability in the blood. ${ }^{36-38}$ Given that tumor cell membranes are generally negatively charged, when DLD-Lips aggregate at the tumor site $(\mathrm{pH}$ 6.8) via the EPR effect, the DLD-Lips charge conversion should enhance cellular uptake. ${ }^{25,39}$ The charge recovery is attributed to the acid-labile cleavage of the amide formed between amine and DMA. It may be concluded that DLDliposomes are negatively charged $(\mathrm{pH} 7.4)$ while circulating in the blood stream, and the charge will be reversed to positive in the weakly acidic tumor microenvironment and endosomal compartment. Compared with other acidsensitive chemical bonds, such as hydrazine-modified liposomes cleaved at $\mathrm{pH} 5.0$, the amide formed between amine and DMA has an effect on the weakly acidic tumor microenvironment ( $\mathrm{pH}$ 6.8), showing an ideal $\mathrm{pH}$ response. ${ }^{19,40}$

\section{Differential Scanning Calorimetry Analysis}

Figure 1D shows that the characteristic melting point of SPC was approximately $230^{\circ} \mathrm{C}$, that of cholesterol was approximately $150^{\circ} \mathrm{C}$, DSPE-PEG was approximately $54^{\circ}$ $\mathrm{C}$, and that of DLD was about $50^{\circ} \mathrm{C}$. The melting point peak of HYP was approximately $255^{\circ} \mathrm{C}$. The melting points of the above compounds are consistent with those reported in the literature. ${ }^{41-44}$ The above five characteristic peaks appear in the DLD/HYP-Lip physical mixed sample. The characteristic melting point peak of DLD/HYP-Lip powder appeared at approximately $210^{\circ} \mathrm{C}$, which was different from the curve of the physical mixture. Displacement occurred and it is speculated that the DLD/ 
HYP-Lip powder was not undergoing pure physical mixing. The findings also showed that the preparation of DLD/ HYP-Lip was successful.

\section{Characteristics of HYP Release Behavior}

The release characteristics of drug-loaded HYP liposomes in release media with different $\mathrm{pH}$ values were determined. The results shown in Figure 1E indicated that the cumulative release of HYP in DLD/HYP-Lips at all $\mathrm{pH}$ values was about $20 \%$ after $24 \mathrm{~h}$, indicating that the weak acidic release medium only promoted the charge reversal without destroying the liposome structure to promote drug release. Release of HYP from DLD/HYP-Lips at all $\mathrm{pH}$ values was about $50 \%$ after $48 \mathrm{~h}$, and release of HYP from DLD/HYPLips at all $\mathrm{pH}$ values was about $60 \%$ after $72 \mathrm{~h}$. Therefore, DLD-Lips not only had the function of charge reversal, but also maintained the sustained release of HYP. This sustained release can prevent the sudden release of the carrier during the delivery process in the body and increase the accumulation of the drug in the tumor tissue. ${ }^{45,46}$

\section{Protein Adsorption Test Results}

The properties of the liposome surface have a greater impact on the amount of protein adsorption, and the interaction between them indirectly reflects its circulation time in the blood. If the adsorption of non-specific proteins on the liposome surface is reduced, its circulation time in the blood will be prolonged. ${ }^{47,48}$ Therefore, we used the BCA protein experiment to determine the amount of protein adsorbed on the liposome surface. BSA was used as a model protein to simulate plasma protein. The isoelectric point of BSA is 4.5-5.0, ${ }^{49}$ under the conditions of $\mathrm{PH} 7.4$ and 6.8, the PI value is less than the isoelectric point (PI), and BSA surface is negatively charged, the pHs will not affect the charge on the surface of the BSA, so in cell adhesion experiments and blood compatibility experiments, BSA is usually used as a model protein to detect the protein adsorption capacity of liposomes under the condition of $\mathrm{pH} 7.4$ and 6.8. As shown in Figure 1F, at a physiological $\mathrm{pH} 7.4$, after protein and liposomes were incubated for $2 \mathrm{~h}$, the amount of protein adsorption on the surface of SPC-Lip was $(60.97 \pm 2.86)$, DLD-Lip was $(30.10 \pm 2.14)$, DLD-Lip was significantly less than that on the SPC-Lip surface. When the incubation time was extended to $4 \mathrm{~h}$, the amount of protein adsorption on the surface of SPC-Lip was (59.84 \pm 3.59$)$, DLD-Lip was $(34.87 \pm 2.91)$, the protein adsorption capacity of SPC-Lip and DLD-Lip did not increase significantly compared with $2 \mathrm{~h}$, and the change of the test group was the same as 2 h. However, when the liposome and protein were coexposed at $\mathrm{pH} 6.8$ after 2 hours of incubation, the amount of protein adsorption on the surface of SPC-Lip was (54.89 \pm 2.94$)$, DLD-Lip was $(69.98 \pm 5.07)$, the interaction between DLD-Lip and protein was strong, and about $70 \%$ of the protein was absorbed by the liposome surface. When the incubation time was extended to $4 \mathrm{~h}$, the amount of protein adsorption on the surface of SPC-Lip was (57.60 \pm 3.70$)$, DLD-Lip was (79.04 \pm 6.10$)$, the interaction between DLD-Lip and protein was also strong, and about $80 \%$ of the protein was absorbed by the liposome surface. The results prove that the change of DLD charge leads to the change of protein adsorption effect. These results are consistent with DLD-Lip's charge reversal phenomenon at $\mathrm{pH} 6.8$.

\section{Cellular Uptake}

In order to observe the in vitro uptake of DLD/HYP-Lip by CBRH-7919 cells, the auto fluorescence of HYP was used as a fluorescence marker, and the cell uptake of DLD/ HYP-Lip was investigated by flow cytometry. Fluorescent intensity was quantified in the diagram. Varied fluorescent intensities were used to indicate liposome uptake. The results of the cell uptake analysis for DLD/HYP-Lip were shown in Figure 2A and B. For ordinary liposomes, the $\mathrm{pH}$ did not change the uptake. In contrast, DLD/HYPLips were greatly affected by the $\mathrm{pH}$ of the environment. The average fluorescence intensity of SPC/HYP-Lips was similar in CBRH-7919 cells. When the $\mathrm{pH}$ value was 7.4, few liposomes were taken up by the CBRH-7919 cells, and the average fluorescence intensity was $(9.81 \pm 0.71)$. At $\mathrm{pH}$ 6.8, liposome internalization increased seven times, and the average intensity was $(70.41 \pm 4.96)$. This may be due to the charge reversal effect of DLD in the slightly acidic environment of the tumor. Under $\mathrm{pH}$ 6.8, the negative charge on the surface of DLD was reversed to a positive charge, promoting cell uptake. The results indicate that DLD/HYP-Lip is sensitive to $\mathrm{pH}$, which specifically increase the uptake of HYP in tumor cells in the tumor microenvironment, and improve the effect of the tumor treatment.

Cellular uptake pathways were identified, results showed that all of the cellular uptake of DLD/HYP-Lip decreased remarkably in the presence of amiloride $(p<0.05)$, an inhibitor of macropinocytosis, and similar phenomena was 

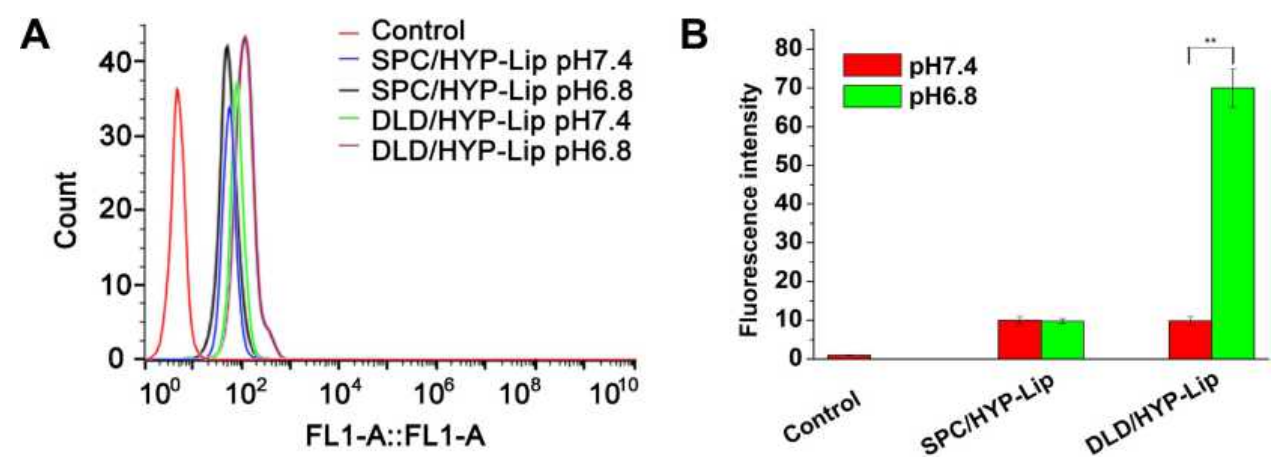

Figure 2 Cellular uptake of DLD/HYP-Lip in CBRH-79I9 cells measured quantitatively using FCM $(\mathbf{A}$ and $\mathbf{B})$. Data are presented as means \pm SD $(n=3)$. $* *<<0.01$.

observed in the presence of chlorpromazine, an inhibitor of clathrin-mediated endocytosis. In contrast, the presence of filipin, an inhibitor of caveolin-mediated endocytosis, had no significant effect on the cellular uptake of DLD/HYP-Lip. It was speculated that DLD-Lips would enter the cells initially in macropinosomes and clathrin coated vesicles by macropinocytosis and clathrin-dependent endocytosis, respectively, and both further in endosomes/lysosomes. Owing to DLD conjugate containing lysines, DLD-Lips might perform the proton sponge effect similar to polyethylenimine (PEI) which leads to the swelling and disruption of the endosomes/ lysosomes for cytoplasmic liberation of the intact liposomes. ${ }^{50,51}$ It is noteworthy that internalization through macropinocytosis is more efficient than that through clathrinmediated endocytosis, since more porous membrane structure of macropinosomes can enhance leakage of inclusions into cytoplasm compared with clathrin-coated nanocarriers, in terms of avoiding endosomal/lysosomal degradation. ${ }^{52,53}$ The experiment content and results (Figure S1) of "Identification of cellular uptake pathways" are shown in Supporting Information.

In order to prove the potential of the prepared mitochondrial targeting liposome DLD/HYP-Lip in tumor treatment, the endosomal escape of the mitochondrial part was studied by confocal fluorescence microscopy. As shown in result (Figure S3) of Supporting Information the incubation time increases, more particles were released into the cytoplasm (red dots in the merged image), indicating that liposomes escape from the lysosome. The results show that DLD/HYPLip can successfully target mitochondria, and DLD play a vital role in the targeting process.

\section{In vitro Cytotoxicity Study}

Through the MTT test, the cytotoxicity of blank DLD-Lips to CBRH-7919 cells with different lipid concentrations was evaluated at $\mathrm{pH} 7.4$ and 6.8 , and the viability of untreated cells at a specific $\mathrm{pH}$ is $100 \%$. Figure $3 \mathrm{~A}$ shows a blank DLD-Lips, even at high lipid concentrations under two $\mathrm{pH}$ conditions, were non-toxic; therefore, DLD-Lips may be a safe drug delivery system. The MTT method was also used to evaluate the cytotoxicity of HYP, SPC/HYP-Lips, and DLD/HYP-Lips to liver cancer CBRH-7919 cells at $\mathrm{pH}$ 7.4 and 6.8. At pH 6.8, Figure 3B-D show that DLD/HYPLips was also more cytotoxic to CBRH-7919 cells than HYP and SPC/HYP-Lips. DLD/HYP-Lips promoted the death of CBRH-7919 cells. Therefore, these data are consistent with the data from cell uptake studies. In addition, the $\mathrm{pH}$-induced surface charge reversal of liposomes contributed to the internalization of liposomes and the accumulation of anticancer drugs in cells. DLD/HYP-Lips $\mathrm{IC}_{50}$ of CBRH-7919 cells were eight times lower than HYP at the same $\mathrm{pH}$. HYP, SPC/HYP-Lips, and DLD/HYP-Lips. IC $_{50}$ of CBRH-7919 cells were $4.89 \mu \mathrm{g} / \mathrm{mL}, 13.82 \mu \mathrm{g} / \mathrm{mL}, 18.08 \mu \mathrm{g} / \mathrm{mL}$ at $\mathrm{pH} 7.4$; HYP, SPC/HYP-Lips, and DLD/HYP-Lips $\mathrm{IC}_{50}$ of CBRH7919 cells were $4.59 \mu \mathrm{g} / \mathrm{mL}, 12.91 \mu \mathrm{g} / \mathrm{mL}, 0.26 \mu \mathrm{g} / \mathrm{mL}$ at $\mathrm{pH}$ 6.8. Therefore, DLD/HYP-Lips had the greatest inhibitory effect on the growth of CBRH-7919 cells, especially at $\mathrm{pH}$ 6.8. This enhanced inhibitory effect can be attributed to the higher intracellular uptake by targeting mitochondria to trigger apoptosis.

\section{Mitochondrial Targeting by Confocal Laser Scanning Microscopy(CLSM)}

To determine whether the enhanced anticancer effect of DLD Lips stemmed from the mitochondria-mediated apoptosis pathway, mitochondrial targeting was first examined with a CLSM and flow cytometry (FCM). Figure 4A shows CLSM images of mitochondria localization of DLD/HYP-Lips in CBRH-7919 cells. Yellow dots indicate co-localization of green fluorescence from Mitotracker Green FM and red fluorescence from DLD/HYP-Lips. Bright yellow fluorescence indicates that DLD/HYP-Lips 
A

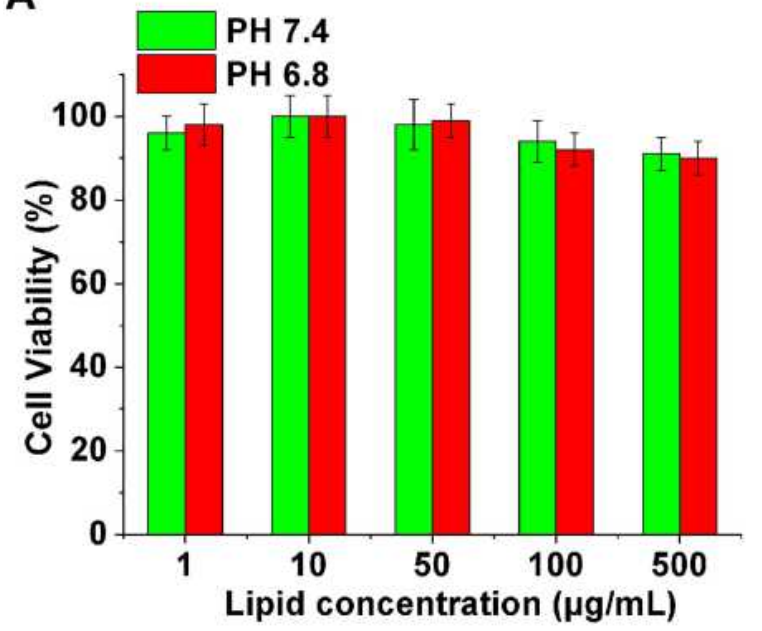

C

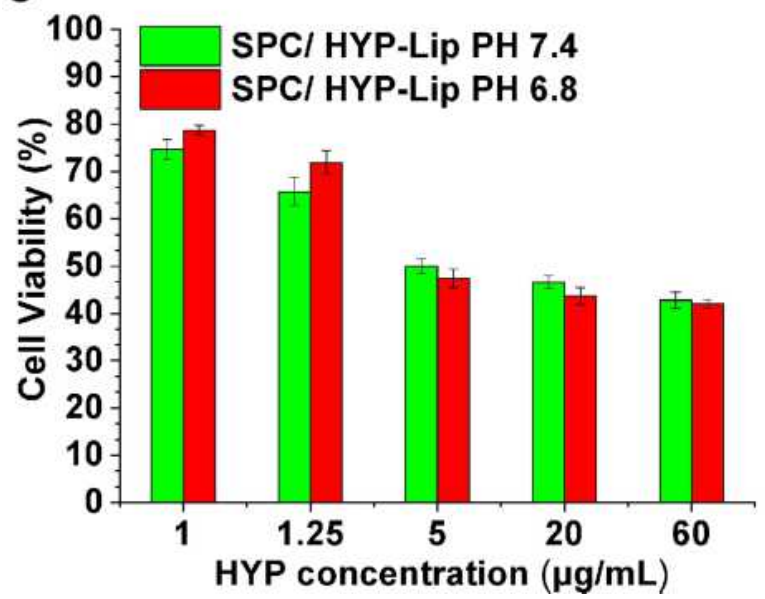

B

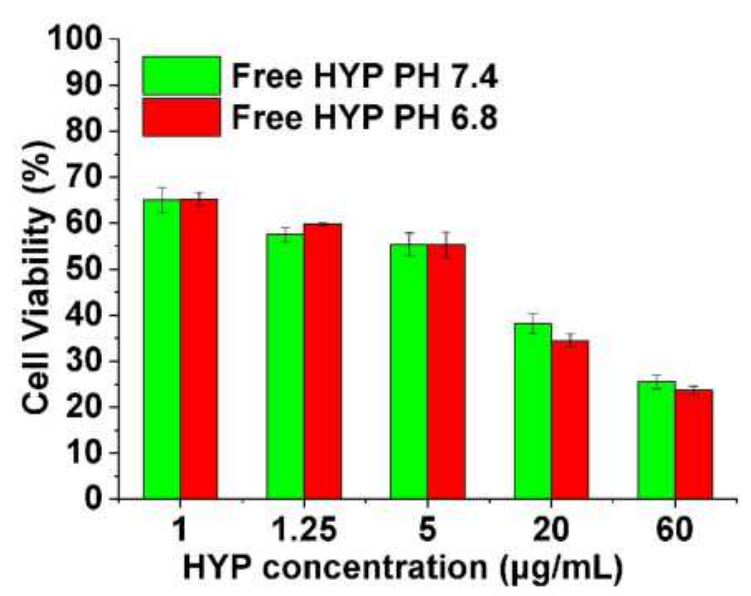

D

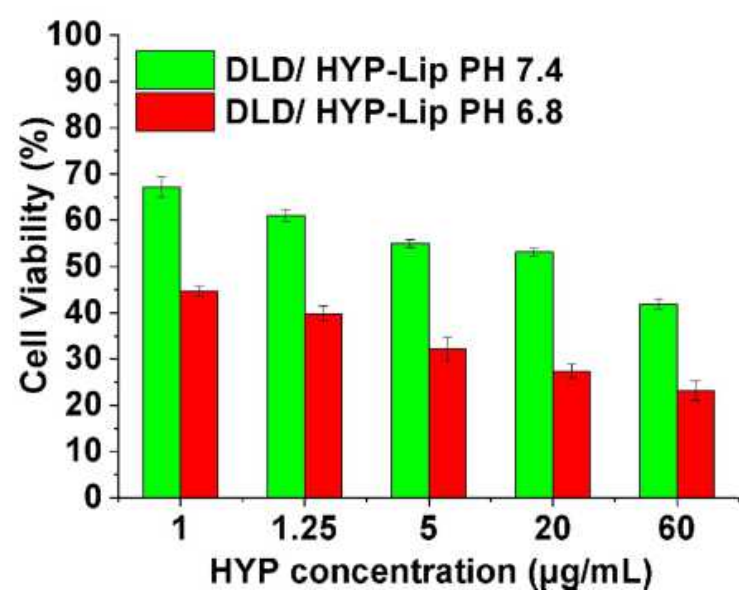

Figure 3 Cytotoxicity of SPC solution (A), HYP solution (B), SPC/HYP-Lip (C), and DLD/HYP-Lips (D) (pH 7.4 and pH 6.8) on CBRH 79/9 (means \pm SD, n=3).

selectively accumulated into mitochondria and that SPC/ HYP-Lips (no yellow fluorescence) did not.

\section{HYP Content in Mitochondria}

Mitochondria are the main site for cells to perform aerobic respiration and adenosine triphosphate (ATP) are formed by oxidative phosphorylation. ${ }^{54}$ The mitochondrion is also an organelle that is capable of reproducing in eukaryotic cells. Mitochondria control apoptosis and many lethal signaling pathways focus on mitochondria. ${ }^{55}$ The discovery of the mechanism of mitochondrial regulation of apoptosis has made it a broad prospect for anti-tumor targets. ${ }^{56-58}$ Studies had shown that the occurrence and development of tumors were apoptosis-related, and mitochondria had a regulatory effect on apoptosis. ${ }^{59,60}$

Figure 4B and C, respectively, indicated the cumulative amount of the drug in the exfoliated mitochondria of CBRH7919 cells, which was expressed by the amount of fluorescence intensity. After the cells were incubated with DLD/HYP-Lips for a period of time, the fluorescence intensity in the mitochondria was significantly higher than that in the SPC/HYP-Lips group. The fluorescence intensity was (65.16 \pm 5.07 ), which was approximately 3.4 times higher than that of the SPC/HYP-Lips group $(18.23 \pm 1.59)$. The above data indicate that DLD-Lips can effectively target mitochondria and increase the accumulation of drugs in the mitochondria.

The content of HYP in the mitochondria of tumor tissue was also determined, results (Figure S2) showed that the content of HYP in tumor tissue mitochondria in the DLD/HYPLip administration group was significantly higher than saline group, HYP and SPC/HYP-Lip group. The results indicate that DLD/HYP-Lip can be enriched in the mitochondria of the tumor tissue, which enhances the toxicity of DLD/HYP-Lip to tumor tissue. The experiment content and results are shown in Supporting Information. 
A
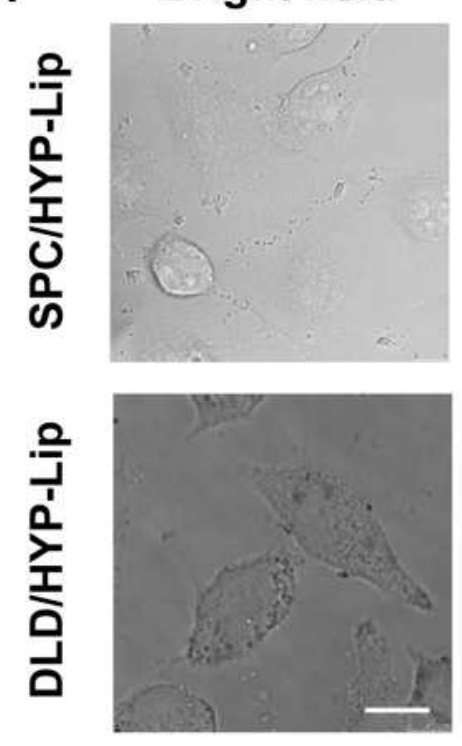

HYP
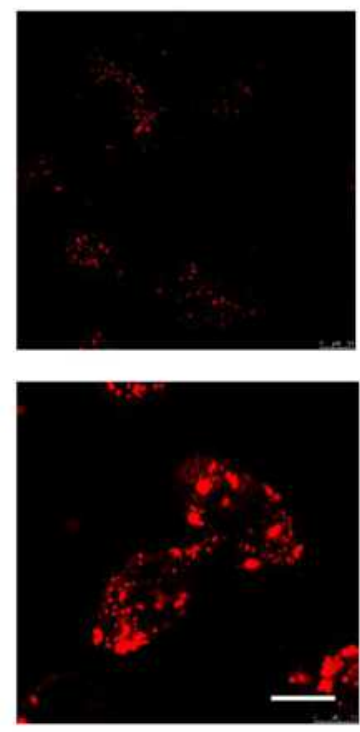

Mitochondrial
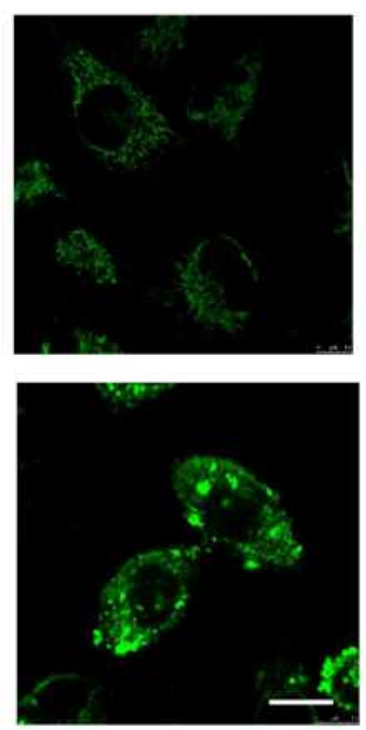

Merged
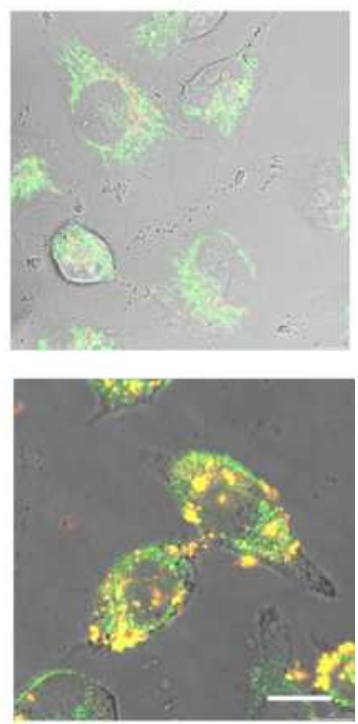

B

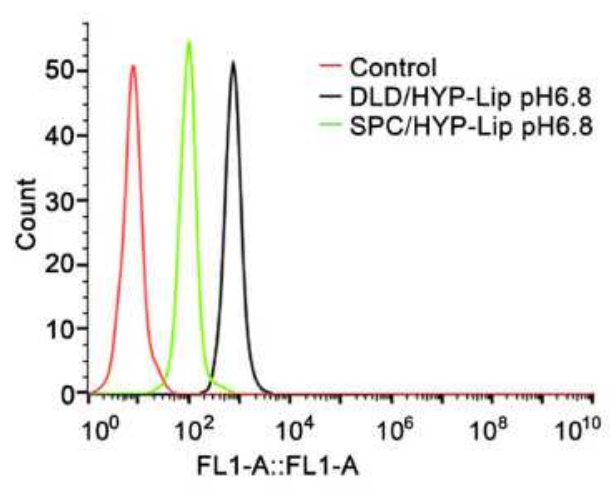

D

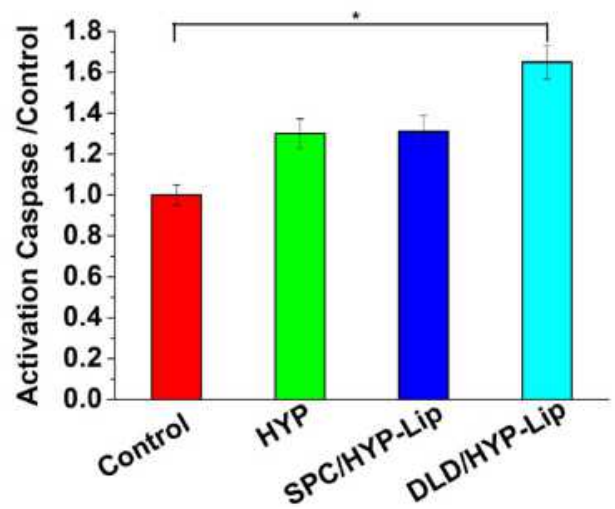

C

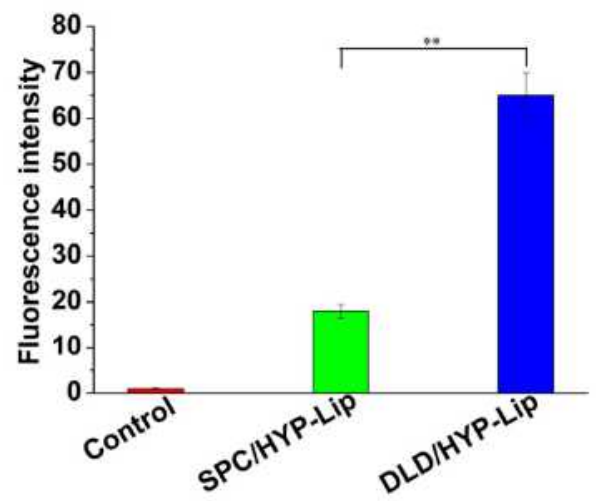

E

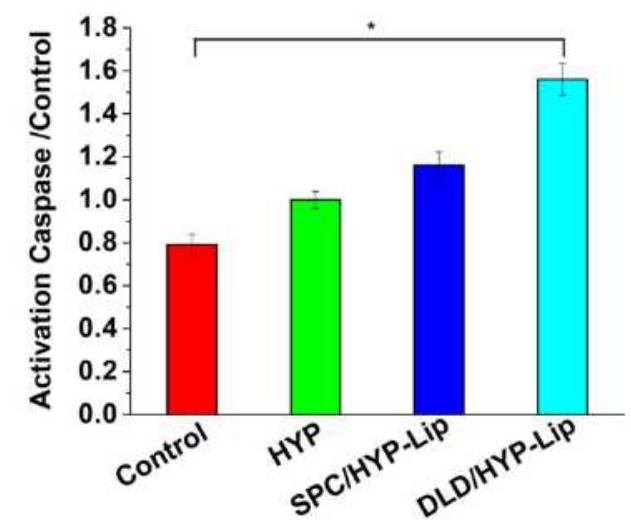

Figure 4 Mitochondrial targeting of liposomal formulations. Mitochondrial localization of DLD/HYP-Lips in CBRH-79/9 cells by confocal laser scanning microscopy. CBRH7919 cells were incubated with SPC/HYP-Lips and DLD/HYP-Lips for $12 \mathrm{~h}$ and then stained with Mitotracker Green FM. Yellow spots in the merged pictures denote the colocalization of the liposomes within mitochondrial compartments. The scale bar represents $25 \mu \mathrm{m}(\mathbf{A})$. The cumulative amount of HYP in mitochondria of CBRH-79I9 cells at $\mathrm{pH} 6.8$ measured by flow cytometry $(\mathbf{B}$ and $\mathbf{C})$. Activity ratios of caspase $9(\mathbf{D})$ and caspase $3(\mathbf{E})$. Data are presented as means \pm SD $(\mathrm{n}=3)$. ${ }^{*} \mathrm{p}<0.05, * * \mathrm{p}<0.0 \mathrm{I}$. 


\section{Activity Determination of Caspase 3 and Caspase 9}

The activation of apoptosis-related enzymes is an essential factor in the process of cell apoptosis, and caspase 9 and caspase 3 are usually used as downstream markers of tumor cell apoptosis. ${ }^{61-63}$ Figure 4D and E, respectively, reflect the caspase 9 and caspase 3 activities of CBRH-7919 cells treated with different HYP preparations. After treatment with DLD/HYP-Lips, the caspase 9 activity ratio in CBRH7919 cells was 1.68 times higher than that in the control group, while the caspase 3 activity ratio increased by 1.97 times compared to the control group. Compared with other HYP preparations, DLD/HYP-Lips had the most significant effect of inducing caspase 9 and caspase 3 activation. These data show that cell death induced by DLD/HYP-Lip is mediated by mitochondrial-dependent apoptosis pathways.

\section{Cell Apoptosis}

The early and late apoptotic cells were counted to prove that HYP induced apoptosis of liver cancer CBRH-7919 cells
(Figure 5A-E). When HYP, SPC/HYP-Lip, and DLD/HYPLip $(6.0 \mathrm{mg} / \mathrm{mL}$ HYP) were used, the apoptosis induction rate was $24.44 \%, 10.28 \%$, and $41.38 \%$, respectively. In addition, blank DLD-Lip induced apoptosis at a rate of $1.52 \%$, which was similar to the control group $(0.96 \%)$. Results indicate that blank DLD-Lips have no direct effect on cell apoptosis. In addition, DLD concentrate liposomes in cells, exert cytotoxic function, and promoted cell apoptosis, suggesting that DLD/HYP-Lip-induced cell death is mediated by a mitochondrial-dependent apoptosis pathway.

\section{In vivo Antitumor Efficacy}

In order to confirm the feasibility of DLD/HYP-Lips for cancer therapy in vivo, tumor xenograft models were used to evaluate the antitumor efficacy of DLD/HYP-Lips in vivo. The anti-tumor effect was reflected by measuring the changes in tumor volume of tumor-bearing nude mice in each test group within 25 days (Figure 6A). The tumors of nude mice in the saline injection group grew very fast. Both HYP and SPC/HYP-Lip inhibited tumor growth to a certain extent,
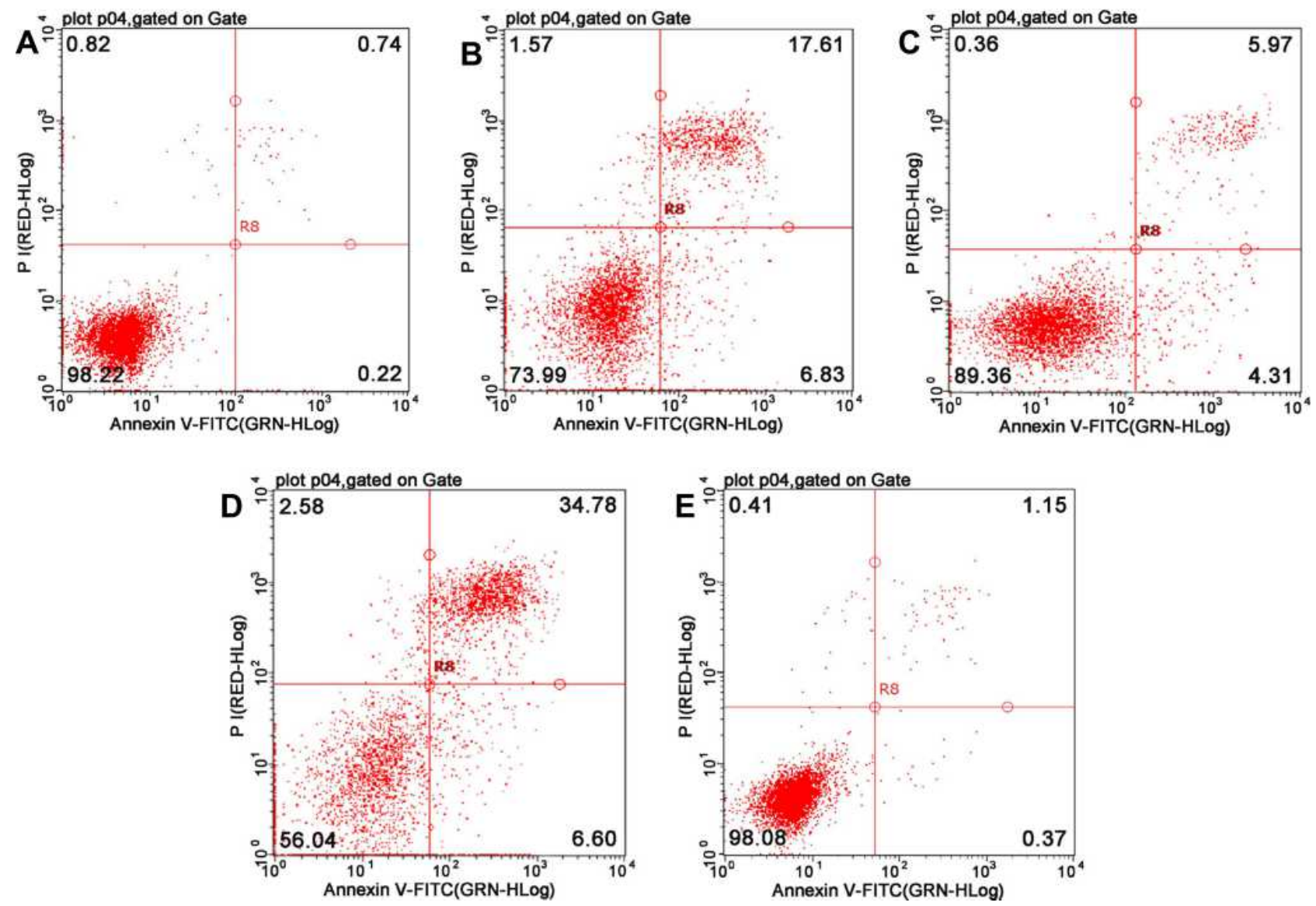

Figure 5 Cell apoptosis of CBRH-7919 cells (A-E) treated with the culture medium, HYP, SPC/HYP-Lip, DLD/HYP-Lip, and DLD-Lip for $12 \mathrm{~h}$ and determined using flow cytometry. 
A

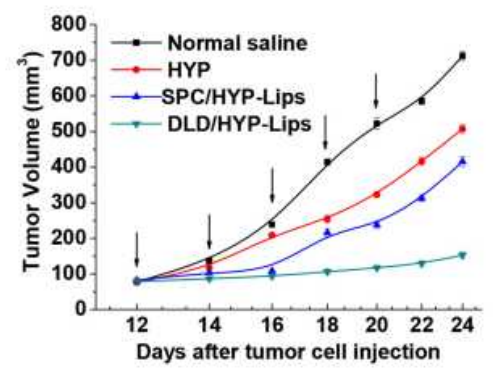

D

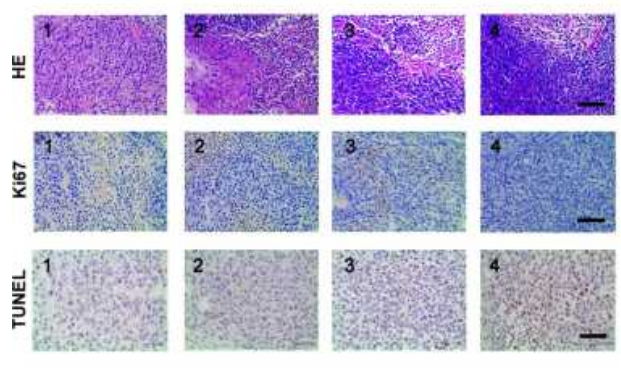

B

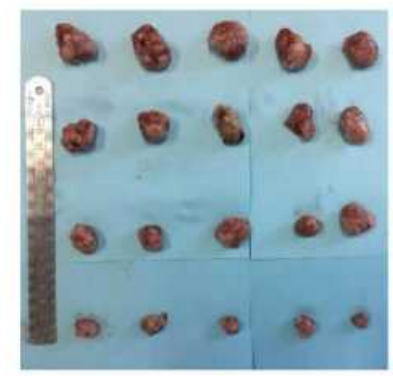

E

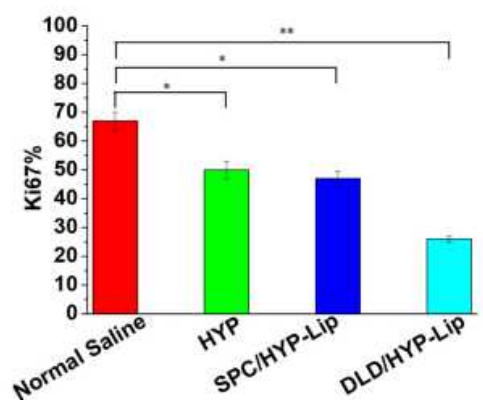

C

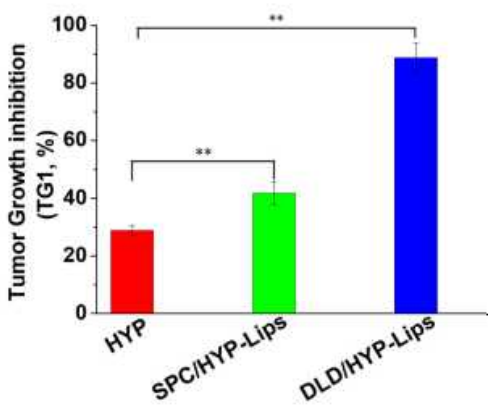

F

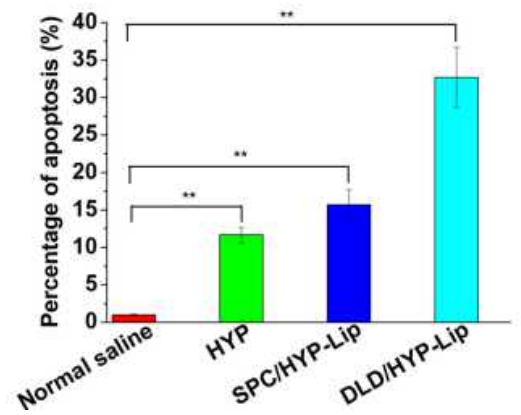

Figure 6 In vivo antitumor efficacy of various HYP formulations in CBRH-79/9 cell tumor-bearing mice. Mice $(n=5)$ received injections of HYP $(6.0$ mg/kg) as indicated by the arrows. Tumor growth as a function of time (A); tumors were photographed at the end of the experiment (B). Tumor tissues were isolated and tumor growth inhibition (TGI, \%) was calculated (C); morphological changes in HE stained sections of tumors (D); evaluation of tumor cell proliferation in vivo using Ki67 staining (proliferative cells shown in brown (D). The Ki67 index was calculated as the ratio of proliferative cells to total cells in each field $(n=5)(E)$. Evaluation of tumor cell apoptosis in vivo using a TUNEL assay (apoptotic cells shown in brown) (D); percentage of apoptotic index was calculated as the ratio of apoptotic cells to total cells in each field ( $\mathrm{n}=5$ ) $(\mathbf{F})$. I. Saline, 2. HYP, 3. SPC/HYP-Lips and 4. DLD/HYP-Lips treatment. Results are presented as means \pm SD, $*_{p}<0.05$, $*^{*} \mathrm{p}<0.01$. Scale bars represent $250 \mu \mathrm{m}$.

while DLD/HYP-Lip almost completely inhibited tumor growth, indicating that DLD/HYP-Lip had a significant anticancer effect. Photographs of the tumors at day 25 are shown in Figure 6B, as are the growth curves of the tumors.

After the experiment, the tumors in each drug group were stripped and weighed to calculate the tumor inhibition rate (Figure 6C). The tumor inhibition rates of HYP, SPC/HYP-Lip, and DLD/HYP-Lip were $28.78 \%, 41.71 \%$, and $88.79 \%$, respectively. The findings showed that DLD/ HYP-Lip has the best anti-tumor effect.

After the tumor suppression experiment in tumor-bearing nude mice was completed, we excised the tumor tissue and performed immunohistochemical staining. As shown in Figure 6D, the HE experimental results showed that DLD/ HYP-Lips caused the largest area of apoptosis in drugresistant tumor tissue. The Ki67 immunohistochemical staining experiment showed that tumor-bearing nude mice injected with DLD/HYP-Lip showed a significantly reduced proliferation level of tumor cells (Figure 6E). The TUNEL test showed that tumor-bearing nude mice injected with DLD/HYP-Lip more significantly induced apoptosis of drug-resistant tumor cells (Figure 6F). The reasons of enhanced efficacy of DLD/ HYP-Lip may be as follows: (1) Negatively charged DLD/ HYP-Lips in the circulation interact less with plasma proteins, so it could resist non-specific protein absorption and escape RES rapid elimination; (2) Suitable particle sizes of DLD/ HYP-Lips could induce greater accumulation of HYP into tumor tissue ( $\mathrm{pH}$ 6.8) via the EPR effect and chargeconversion increase cellular uptake of DLD/HYP-Lips to enhance cytotoxicity in liver cancer cells; (3) Apoptosisinducing effect of DLD/HYP-Lips could increase anticancer efficacy.

\section{In vivo Toxicity Assays on Normal Mice}

Healthy tumor-free BALB/c mice were used to evaluate the toxicity of HYP, SPC/HYP-Lip, and DLD/HYP-Lip $(6.0 \mathrm{mg} /$ $\mathrm{kg}$ HYP) in vivo. The clinical toxicity behavior and body weight changes of the mice during the administration period were recorded. After the end of the final observation period, the organs were excised for HE staining experiments. Compared with the control group, there was no obvious dehydration, dyskinesia, muscle loss, anorexia, or other animal toxicity- 
A

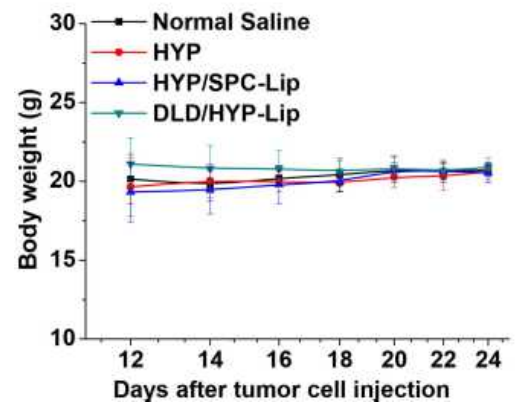

B

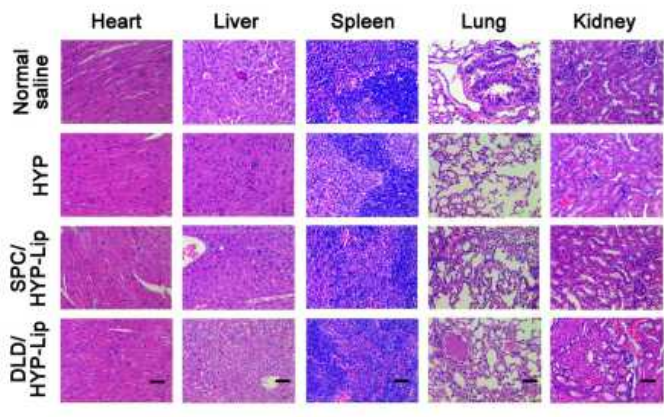

Figure 7 In vivo toxicity assays in normal mice. Body weight curves of mice receiving different treatments (HYP $6.0 \mathrm{mg} / \mathrm{kg}$ ) (A). Morphological changes in HE stained of different organs of normal mice with different treatments (B). I. Normal saline, 2. HYP, 3. SPC/HYP-Lip, 4. DLD/HYP-Lip. Scale bars represent 250 $\mu$ m.

related symptoms during the administration period. The body weight changes of tumor-bearing nude mice in each group are shown in Figure 7A. The body weight of mice in each administration group increased slightly, indicating that there was likely no serious systemic toxicity in each drug delivery system. The results of the HE staining experiment showed that the organs of the mice in each administration group did not show significant damage (Figure 7B).

\section{Conclusions}

In the present study, a dual-function tumor-targeting liposomes (DLD-HYP-Lips) has been developed, in which HYP was delivered to the mitochondria of tumor cells to enhance anticancer activity. Unlike most therapeutic liposomes that exerted function at the cellular level, our HYP loaded DLD-Lips target the mitochondria at the subcellular level for more effective treatment. The results showed that DLD-Lips can be oriented to mitochondria by modification with a pH-responsive phospholipid DSPE-Lys-DMA. Compared to free HYP and HYPloaded traditional liposomes, HYP loaded DLD-Lips increased cytotoxicity of liver cancer CBRH-7919 cells and antitumor effect in vivo. This was due to increased cellular uptake and mitochondria-mediated apoptosis, which obviously decreased mitochondrial membrane potential, activation of caspase-9/3 and induced apoptosis. Therefore, DLD-Lip is a promising anticancer drug delivery system to cancer therapy both in vitro and in vivo.

\section{Acknowledgment}

This study was financially supported by the National Natural Science Foundation of China (No. 81703944), Heilongjiang Natural Science Foundation Project (YQ2019H031), Post- doctoral Researchers Settled in Heilongjiang Scientific Research Startup Fund (2020), and Outstanding Innovative Talents Project from Heilongjiang University of Chinese medicine (2018).

\section{Disclosure}

The authors report no conflicts of interest in this work.

\section{References}

1. Schmid P, Abraham J, Chan S, et al. Capivasertib plus paclitaxel versus placebo plus paclitaxel as first-line therapy for metastatic triple-negative breast cancer: the pakt trial. J Clin Oncol. 2020;38 (5):423-433. doi:10.1200/JCO.19.00368

2. Lau TS, Chan LKY, Man GCW, et al. Paclitaxel induces immunogenic cell death in ovarian cancer via $\mathrm{TLR}_{4} / \mathrm{IKK}_{2} / \mathrm{SNARE}$-dependent exocytosis. Cancer Immunol Res. 2020;8(8):1099-1111. doi:10.1158/ 2326-6066.CIR-19-0616

3. Zhong Y, Qi HL, Li XJ, et al. Tumor supernatant derived from hepatocellular carcinoma cells treated with vincristine sulfate have therapeutic activity. Eur J Pharm Sci. 2020;155:105557. doi:10.1016/ j.ejps.2020.105557

4. Chen D, Wu YX, Qiu YB, et al. Hyperoside suppresses hypoxia-induced A549 survival and proliferation through ferrous accumulation via AMPK/HO-1 axis. Phytomedicine. 2020;67:153138. doi:10.1016/j.phymed.2019.153138

5. Sun T, Liu YY, Li MD, et al. Administration with hyperoside sensitizes breast cancer cells to paclitaxel by blocking the TLR4 signaling. Mol Cell Probes. 2020;53:101602. doi:10.1016/j.mcp.2020.101602

6. Lü P. Inhibitory effects of hyperoside on lung cancer by inducing apoptosis and suppressing inflammatory response via caspase-3 and NF-kB signaling pathway. Biomed Pharmacother. 2016;82:216-225. doi:10.1016/j.biopha.2016.05.006

7. Yang Y, Tantai JC, Sun YF, et al. Effect of hyperoside on the apoptosis of A549 human non-small cell lung cancer cells and the underlying mechanism. Mol Med Rep. 2017;16(5):6483-6488. doi:10.3892/ mmr.2017.7453

8. Dai PP, Chen JQ. Research progress of anti-tumor effects and immunomodulatory effects of hyperoside. Med Recapitulate. 2014;20 (11):1979-1981.

9. Chen SY, Song ZM, Feng RL. Recent development of copolymeric nano-drug delivery system for Paclitaxel. Anti Cancer Agents Med Chem. 2020;20(18):2169-2189. 
10. Li J, Wu X, Peng Q, et al. Liposome coated mesoporous carbon nanotube with resveratrol loading for targeted and near-infrared laser-triggered chemo/photothermal synergistic cancer therapy. Acta Laser Biol Sin. 2020;29(6):550-560.

11. Cheng N, Bai XX, Shu YX, et al. Targeting tumor-associated macrophages as an antitumor strategy. Biochem Pharmacol. 2021;183:114354. doi:10.1016/j.bcp.2020.114354

12. Ding XY, Yin CY, Zhang WW, et al. Designing aptamer-gold nanoparticle-loaded ph-sensitive liposomes encapsulate morin for treating cancer. Nanoscale Res Lett. 2020;15(1):68. doi:10.1186/ s11671-020-03297-x

13. Chen S, Zhang TY, Yang M, et al. PH-sensitive nano-drug delivery systems for cancer therapy. Chem Life. 2020;40(3):358-368.

14. Zhang L, Wang SJ. Preparation of docetaxel targeting liposomes and its effect on pharmacokinetics in vivo. Chin Clin Ration Drug Use. 2020;13(11):167-169.

15. Liang HM, Zou FM, Liu QW, et al. Nanocrystal-loaded liposome for targeted delivery of poorly water-soluble antitumor drugs with high drug loading and stability towards efficient cancer therapy. Int J Pharm. 2021;599:120418. doi:10.1016/j.ijpharm.2021.120418

16. Shen ZQ, Ye HL, Kröger M, et al. Aggregation of polyethylene glycol polymers suppresses receptor-mediated endocytosis of PEGylated liposomes. Nanoscale. 2018;10(9):4545-4560. doi:10.1039/C7NR09011K

17. Jimenez-Lopez J, Bravo-Caparros I, Cabeza L, et al. Paclitaxel antitumor effect improvement in lung cancer and prevention of the painful neuropathy using large pegylated cationic liposomes. Biomed Pharmacother. 2021;133:111059. doi:10.1016/j.biopha.2020.111059

18. Karve S, Bandekar A, Ali MR, et al. The pH-dependent association with cancer cells of tunable functionalized lipid vesicles with encapsulated doxorubicin for high cell-kill selectivity. Biomaterials. 2010;31(15):4409-4416. doi:10.1016/j.biomaterials.2010.01.064

19. Kanamala M, Palmer BD, Ghandehari H, et al. PEG-benzaldehydehydrazone-lipid based PEG-sheddable pH-sensitive liposomes: abilities for endosomal escape and long circulation. Pharm Res. 2018;35 (8):154. doi:10.1007/s11095-018-2429-y

20. Long W, Ouyang H, Wan WM, et al. "Two in one": simultaneous functionalization and DOX loading for fabrication of nanodiamondbased $\mathrm{pH}$ responsive drug delivery system. J Mater Sci Eng C. 2020;108:110413. doi:10.1016/j.msec.2019.110413

21. Prabaharan M, Grailer JJ, Pilla S, et al. Amphiphilic multi-arm-block copolymer conjugated with doxorubicin via $\mathrm{pH}$-sensitive hydrazone bond for tumor-targeted drug delivery. Biomaterials. 2009;30 (29):5757-5766. doi:10.1016/j.biomaterials.2009.07.020

22. Kanamala M, Palmer BD, Wilson WR, et al. Characterization of a smart pH-cleavable PEG polymer towards the development of dual pH-sensitive liposomes. Int J Pharm. 2018;548(1):228-296. doi:10.1016/j.ijpharm.2018.07.009

23. Lim CW, Kim D. Bone targeting nano-aggregates prepared from self-assembled polyaspartamide graft copolymers for $\mathrm{pH}$ sensitive DOX delivery. Biomater Sci. 2021;9(5):1660-1667. doi:10.1039/ D0BM01473G

24. Mo R, Sun Q, Li N, et al. Intracellular delivery and antitumor effects of $\mathrm{pH}$-sensitive liposomes based on zwitterionic oligopeptide lipids. Biomaterials. 2013;34(11):2773-2786. doi:10.1016/j.biomaterials.20 13.01 .030

25. Zhou ZX, Shen YQ, Tang JB, et al. Charge-reversal drug conjugate for targeted cancer cell nuclear drug delivery. Adv Funct Mater. 2009;19(22):3580-3589. doi:10.1002/adfm.200900825

26. Zhang QY, Lu LB, Zhang L, et al. Dual-functionalized liposomal delivery system for solid tumors based on RGD and a $\mathrm{pH}$-responsive antimicrobial peptide. Sci Rep. 2016;6(1):19800. doi:10.1038/srep19800

27. Vila-Caballer M, Codolo G, Munari F, et al. A pH-sensitive stearoyl-PEG-poly(methacryloyl sulfadimethoxine)-decorated liposome system for protein delivery: an application for bladder cancer treatment. $J$ Control Release. 2016;238:31-42. doi:10.1016/j. jconrel.2016.07.024
28. Jiang L, He B, Pan DY, et al. Anti-cancer efficacy of paclitaxel loaded in pH triggered liposomes. J Biomed Nanotechnol. 2016;12 (1):79-90. doi:10.1166/jbn.2016.2123

29. Lee Y, Miyata K, Oba M, et al. Charge-conversion ternary polyplex with endosome disruption moiety: a technique for efficient and safe gene delivery. Angew Chem. 2008;47(28):5163-5166. doi:10.1002/ anie. 200800963

30. Du JZ, Du XJ, Mao CQ, et al. Tailor-made dual pH-sensitive polymer-doxorubicin nanoparticles for efficient anticancer drug delivery. J Am Chem Soc. 2011;133(44):17560-17563. doi:10.1021/ ja207150n

31. Wang LM, Wang YX, Zhu QS, et al. Study on the inhibitory effect of hyperoside on tumor-bearing mice. Heilongjiang Med Pharm. 2010;33(2):62.

32. Sun JW, Jiang L, Lin Y, et al. Enhanced anticancer efficacy of paclitaxel through multistage tumor-targeting liposomes modified with RGD and KLA peptides. Int J Nanomed. 2017;12:1517-1537. doi:10.2147/IJN.S122859

33. Tunsirikongkon A, Pyo YC, Kim DH, et al. Effect of calcium chloride on the protein encapsulation and stability of proliposomal granules. $J$ Drug Delivery Sci Technol. 2020;57:101672. doi:10.1016/j.jddst.2020.101672

34. Wang XY, Ma ML. Preparation of arsenic trioxide liposome by active drug-loading method. Chin Tradit Herb Drugs. 2014;45(5):648-651.

35. Cipolla D, Wu HY, Gonda I, et al. Aerosol performance and stability of liposomes containing ciprofloxacin nanocrystals. J Aerosol Med Pulm Drug Delivery. 2015;28(6):411-422. doi:10.1089/jamp.20 15.1241

36. Wang Y, Shen N, Sakurai K, et al. Multi-stimuli-responsive polymeric prodrug for enhanced cancer treatment. Macromol Biosci. 2019;19(12):e1900329. doi:10.1002/mabi.201900329

37. Fang L, Zhang W, Wang Z, et al. Novel mitochondrial targeting charge-reversal polysaccharide hybrid shell/core nanoparticles for prolonged systemic circulation and antitumor drug delivery. Drug Deliv. 2019;26(1):1125-1139. doi:10.1080/10717544.2019.1687614

38. Jiang TY, Zhang ZH, Zhang YL, et al. Dual-functional liposomes based on pH-responsive cell-penetrating peptide and hyaluronic acid for tumor-targeted anticancer drug delivery. Biomaterials. 2012;33 (36):9246-9258. doi:10.1016/j.biomaterials.2012.09.027

39. Du JZ, Sun TM, Song WJ, et al. A tumor-acidity-activated charge-conversional nanogel as an intelligent vehicle for promoted tumoral-cell uptake and drug delivery. Angew Chem. 2010;49 (21):3621-3626. doi:10.1002/anie.200907210

40. Kanamala M, Wilson WR, Yang MM, et al. Mechanisms and biomaterials in pH-responsive tumour targeted drug delivery: a review. Biomaterials. 2016;85:152-167. doi:10.1016/j.biomaterials.20 16.01.061

41. Hashizaki K, Taguchi H, Itoh C, et al. Effects of poly(ethylene glycol) (PEG) chain length of PEG-Lipid on the permeability of liposomal bilayer membranes. Chem Pharm Bull (Tokyo). 2003;51 (7):815-820. doi: $10.1248 / \mathrm{cpb} .51 .815$

42. Venkateswarlu V, Manjunath K. Preparation, characterization and in vitro release kinetics of clozapine solid lipid nanoparticles. J Control Release. 2004;95(3):627-638. doi:10.1016/j.jconrel.20 04.01.005

43. Wu RG, Sun HY, Zhou HW, et al. Interaction between paeonol and liposomes by DSC and XRD techniques II. Chin J Tradit Chin Med. 2015;32(3):14-16.

44. Qiao CY, Zhang CY, Sun YT, et al. A study on the interactions of hyperoside with DNA. Chem Adhes. 2016;38(6):439-449.

45. Wang XX, Li YB, Yao HJ, et al. The use of mitochondrial targeting resveratrol liposomes modified with a dequalinium polyethylene glycol-distearoylphosphatidyl ethanolamine conjugate to induce apoptosis in resistant lung cancer cells. Biomaterials. 2011;32 (24):5673-5687. doi:10.1016/j.biomaterials.2011.04.029 
46. Zhou J, Zhao WY, Ma X, et al. The anticancer efficacy of paclitaxel liposomes modified with mitochondrial targeting conjugate in resistant lung cancer. Biomaterials. 2013;34(14):3626-3638. doi:10.1016/ j.biomaterials.2013.01.078

47. Wang L, Hartel N, Ren KX, et al. Effect of protein corona on nanoparticle-plasma membrane and nanoparticle-biomimetic membrane interactions. Environ Sci Nano. 2020;7(3).

48. Yallapu MM, Ebeling MC, Jaggi M, et al. Plasma proteins interaction with curcumin nanoparticles: implications in cancer therapeutics Curr Drug Metab. 2013;14(4):504-515. doi:10.2174/13892002113 14040012

49. Eroglu EC, Oztop K, Aksay S. Physiochemical properties and ace inhibitory capacity of hazelnut protein isolate and hydrolysates. J Microbiol Biotechnol Food Sci. 2020;10(1):78-82.

50. Sun XY, Chen JL, Chen HL, et al. Polyethylenimine modified liposomes as potential carriers for antitumor drug delivery in vitro. Pharmazie. 2012;67(5):426-431.

51. Sun XY, Chen JL, Gu XH, et al. Efficacy and toxicity of cisplatin liposomes modified with polyethylenimine. Pharmazie. 2014;69 (4):281-286

52. Nakase I, Noguchi K, Aoki A, et al. Arginine-rich cell-penetrating peptide-modified extracellular vesicles for active macropinocytosis induction and efficient intracellular delivery. Sci Rep. 2017;7 (1):1991. doi:10.1038/s41598-017-02014-6

53. Paliwal SR, Paliwal R, Agrawal GP, et al. Hyaluronic acid modified $\mathrm{pH}$-sensitive liposomes for targeted intracellular delivery of doxorubicin. J Liposome Res. 2016;26(4):276-287. doi:10.3109/ 08982104.2015.1117489

54. Murphy MP. How mitochondria produce reactive oxygen species. Biochem J. 2009;417(1):1-13. doi:10.1042/BJ20081386

55. Jiang LZ, Li TL, Hong Y. Advances in research on targeting mitochondria for cancer therapy. Anhui Med Pharm J. 2011;15 (11):1329-1331.
56. Yin PH, Liu X, Qiu YY, et al. Anti-tumor activity and apoptosis-regulation mechanisms of bufalin in various cancers: new hope for cancer patients. Asian Pac J Cancer Prev. 2012;13 (11):5339-5343. doi:10.7314/APJCP.2012.13.11.5339

57. Strohecker AM, Guo YX, Uzunbas GK, et al. Autophagy sustains mitochondrial glutamine metabolism and growth of BrafV600E-Driven lung tumors. Cancer Discov. 2013;3 (11):1273-1285. doi:10.1158/2159-8290.CD-13-0397

58. Braganza A, Quesnelle K, Bickta J, et al. Myoglobin induces mitochondrial fusion, thereby inhibiting breast cancer cell proliferation. J Biol Chem. 2019;294(18):7269-7282. doi:10.1074/jbc.RA118.0 06673

59. Hazafa A, Batool A, Ahmad S, et al. Humanin: a mitochondrial-derived peptide in the treatment of apoptosis-related diseases. Life Sci. 2021;264:118679. doi:10.1016/j.1fs.2020.118679

60. Priwitaningrum DL, Jentsch J, Bansal R, et al. Apoptosis-inducing peptide loaded in PLGA nanoparticles induces anti-tumor effects in vivo. Int $J$ Pharm. 2020;585:119535. doi:10.1016/j.ijpharm.20 20.119535

61. Chen DL, Engle JT, Griffin EA, et al. Imaging caspase-3 activation as a marker of apoptosis-targeted treatment response in cancer. $\mathrm{Mol}$ Imaging Biol. 2015;17(3):384-393. doi:10.1007/s11307-014-0802-8

62. Jiao CW, Chen W, Tan XP, et al. Ganoderma lucidum spore oil induces apoptosis of breast cancer cells in vitro and in vivo by activating caspase-3 and caspase-9. J Ethnopharmacol. 2020;247:112256. doi:10.1016/j.jep.2019.112256

63. Tian YZ, Liu YP, Tian SC, et al. Antitumor activity of ginsenoside $\mathrm{Rd}$ in gastric cancer via up-regulation of caspase-3 and caspase-9. Pharmazie. 2020;75(4):147-150. doi:10.1691/ph.2020.9931
International Journal of Nanomedicine

\section{Publish your work in this journal}

The International Journal of Nanomedicine is an international, peerreviewed journal focusing on the application of nanotechnology in diagnostics, therapeutics, and drug delivery systems throughout the biomedical field. This journal is indexed on PubMed Central, MedLine, CAS, SciSearch ${ }^{\circledR}$, Current Contents ${ }^{\circledR} /$ Clinical Medicine,
Journal Citation Reports/Science Edition, EMBase, Scopus and the Elsevier Bibliographic databases. The manuscript management system is completely online and includes a very quick and fair peer-review system, which is all easy to use. Visit http://www.dovepress.com/ testimonials.php to read real quotes from published authors. 